\title{
Audiovisual links in exogenous covert spatial orienting
}

\author{
CHARLES SPENCE \\ University of Cambridge, Cambridge, England \\ and \\ JON DRIVER \\ Birkbeck College, University of London, London, England
}

\begin{abstract}
Subjects judged the elevation (up vs. down, regardless of laterality) of peripheral auditory or visual targets, following uninformative cues on either side with an intermediate elevation. Judgments were better for targets in either modality when preceded by an uninformative auditory cue on the side of the target. Experiment 2 ruled out nonattentional accounts for these spatial cuing effects. Experiment 3 found that visual cues affected elevation judgments for visual but not auditory targets. Experiment 4 confirmed that the effect on visual targets was attentional. In Experiment 5, visual cues produced spatial cuing when targets were always auditory, but saccades toward the cue may have been responsible. No such visual-to-auditory cuing effects were found in Experiment 6 when saccades were prevented, though they were present when eye movements were not monitored. These results suggest a one-way cross-modal dependence in exogenous covert orienting whereby audition influences vision, but not vice versa. Possible reasons for this asymmetry are discussed in terms of the representation of space within the brain.
\end{abstract}

Mechanisms of attention allow selective processing for events of interest among the cluttered scenes of everyday life. Such events are often specified by information available to several sense modalities simultaneously (e.g., to both audition and vision). However, most attention research has focused on purely unimodal situations, particularly on visual spatial orienting in recent years (see Driver \& Spence, 1994; Klein, Kingstone, \& Pontefract, 1992; Tassinari, Aglioti, Chelazzi, Peru, \& Berlucchi, 1994).

The possible role of audition in orienting has received less investigation, even though sounds may be particularly important for this function, given that our forward-facing eyes provide only restricted peripheral vision. In particular, we may depend upon sound localization for the control of orienting toward significant distal events which occur outside the field of view (Brown \& May, 1989; Harrison \& Irving, 1966) and during occlusion or darkness. Indeed, several investigators have argued that one of the primary functions of sound localization is to direct the eyes (i.e., overt visual orienting) toward auditorily specified events (e.g., Hafter \& De Maio, 1975; Heffner \& Heffner, 1992a, 1992b; Perrott, Saberi, Brown, \& Strybel, 1990).

This work was supported by grants from the Medical Research Council (UK) and by a Junior Research Fellowship awarded to the first author from St. John's College, Cambridge. Our thanks are extended to Zoltan Dienes, Art Kramer, Hermann Müller, and Roger Remington for their helpful comments on earlier drafts of this paper. Correspondence may be addressed to either author: $C$. Spence at the Department of Experimental Psychology, University of Cambridge, Downing Street, Cambridge, CB2 3EB, England (e-mail: cjs1007@cus.cam.ac.uk); J. Driver at the Department of Psychology, Birkbeck College, University of London, London WC1E 7HX, England.
The overt orienting reflex is indeed one of the most reliable behaviors to result from hearing an unexpected sound (e.g., Pumphrey, 1950; Sokolov, 1963; Thompson \& Masterton, 1978), and is found even in newborn infants (Clarkson, Swain, Clifton, \& Cohen, 1991; Muir \& Field, 1979). The response typically involves the coordinated movement of the observer's eyes, head, and body toward the sound source. Such orienting will clearly enhance vision for the foveated stimuli. Perhaps less obviously, the perception of auditory stimuli is also improved in the direction faced by the head and in the direction of gaze (Elfner \& Howse, 1987; Hublet, Morais, \& Bertelson, 1976, 1977; Jones \& Kabanoff, 1975; Mills, 1958; Platt \& Warren, 1972). Such links between overt orienting across vision and audition are consistent with a growing body of neurophysiological evidence for audiovisual interactions in structures known to be involved in overt orienting, such as the superior colliculus (King, 1993; Sparks \& HartwichYoung, 1989; Stein \& Meredith, 1993; Stein, Wallace, \& Meredith, 1995).

A wide range of findings thus demonstrate the importance of hearing, and of audiovisual interactions, in the control of overt orienting. The present investigation examines related questions, but for the case of covert orienting, which occurs without any overt receptor shifts. Covert orienting has been widely studied within vision, using variations on the basic cuing paradigm introduced by Posner (1980). Such work has revealed a distinction between reflexive or exogenous covert orienting (induced by uninformative peripheral cues which do not predict the target locus, but may appear directly at it) and voluntary or endogenous covert orienting (induced by informative 
symbolic cues, such as a central arrow which indirectly predicts the likely target side). Several qualitative differences have now been found between these two forms of covert visual orienting (e.g., Klein, 1994; Müller \& Rabbitt, 1989; Briand \& Klein, 1986; Jonides, 1981), and it is suspected that different neural substrates are involved (e.g., Rafal, Henik, \& Smith, 1991). The present paper focuses on just exogenous covert orienting, defined as that following uninformative peripheral cues. In a companion paper (Spence \& Driver, 1996), we examine related issues for endogenous covert orienting.

The functional importance of sounds for overt orienting, as discussed earlier, raises the possibility that hearing as well as vision may play a role in covert orienting too. However, as discussed at length by Spence and Driver (1994), most existing studies of covert auditory orienting have either reported no spatial cuing effects (e.g., Buchtel \& Butter, 1988; Posner, 1978; Scharf, Quigley, Aoki, Peachey, \& Reeves, 1987) or have found small cuing effects, which remain open to criterion-shift or responsepriming explanations, rather than necessitating any attentional account (e.g., Bédard, El Massioui, Pillon, \& Nandrino, 1993; Mazzuchi, Cattelani, \& Umiltà, 1983; Rhodes, 1987; Simon, Acosta, \& Mewaldt, 1975; Ward, 1994). For instance, when a left/right localization response is required for targets after a cue for one side (Bédard et al., 1993; Ward, 1994), quicker responses for targets on the cued side may arise simply because the cue preactivates the appropriate response rather than because of any shift in covert attention. A recent series of studies with such a method (Quinlan \& Bailey, 1995) did acknowledge this problem, but since all peripheral cues were informative in these studies, specifically exogenous rather than endogenous mechanisms may not have been isolated.

Spence and Driver (1994) recently devised a modified localization task for studying covert orienting in audition. Targets now had to be localized along a dimension that was orthogonal to the dimension of spatial cuing, so that the cue could not preactivate one of the choice responses. As in the studies cited above, subjects were cued toward one side or another with peripheral sounds. However, they now had to discriminate the elevation of the subsequent target sound rather than its laterality. Using this "orthogonal-cuing" method, Spence and Driver (1994, Experiment 2) found that elevation judgments were faster and more accurate for auditory targets appearing shortly after the auditory cue on the same side. This was found even though the cues were spatially uninformative and even though cue-target intervals were too brief to permit eye movements toward the cued side before the target terminated.

These results apparently demonstrate exogenous covert orienting in audition. The experiments in the present paper adapt Spence and Driver's (1994) orthogonalcuing technique to examine any cross-modal audiovisual links in exogenous covert orienting. As discussed earlier, there is abundant evidence for such links in the control of overt orienting to peripheral events. However, the possibility of audiovisual links for covert orienting has been less extensively researched. The few existing studies are reviewed below.

The results of several experiments suggest that uninformative sounds may induce shifts of covert visual attention, analogous to the rapid foveation of sounds in the case of overt orienting. However, all these studies are open to potential criticisms. The first finding is that subjects respond faster in a visual left/right discrimination task when the visual target is accompanied by an uninformative sound on the same rather than opposite side (e.g., Bernstein \& Edelstein, 1971; Simon \& Craft, 1970; but see Ward, 1994). Such a result might be attributed to a shift of covert visual attention toward the peripheral sound. However, shifts of gaze were not controlled in these studies, and thus overt rather than covert orienting may have been responsible for the effects of the sound. Equally, the results might be attributed to the cue merely priming an ipsilateral response.

A second line of evidence is that peripheral sounds that predict the likely side of a visual target can produce cuing effects on simple visual reaction time (Buchtel \& Butter, 1988) similar to the widely studied effects of central visual arrows (Posner, 1980). However, the use of spatially informative cues ( $80 \%$ valid) means that endogenous rather than exogenous covert orienting may have been responsible for the effects in Buchtel and Butter's study. Moreover, the informative auditory cues may have produced just a strategic shift in purely visual attention to the probable target side, exactly like that which would follow the interpretation of a central visual arrow. If so, these results would have no implications for the existence of hardwired, structural links between audition and vision in the control of covert attention (see Driver \& Spence, 1994, for a more detailed version of this argument). Instead, Buchtel and Butter's findings may only show that a sound can be interpreted as a useful instruction about where visual events are most likely to be.

This criticism does not apply to studies that have used uninformative peripheral sounds $(50 \%$ valid regarding target side) as cues in a visual detection task. Klein, Brennan, and Gilani (1987) found that such cues affect simple visual reaction time (RT) for normal subjects, in a manner analogous to visual uninformative cues. Farah, Wong, Monheit, and Morrow (1989) made a similar observation in unilateral parietal patients. The natural interpretation of these results is that the peripheral sounds produced exogenous covert visual orienting. However, several methodological doubts can be raised. In the patient study (Farah et al., 1989), fixation was not monitored, so the results might reflect overt rather than covert orienting toward the peripheral sounds. Various intervals between cue onset and target onset were used in this experiment, some of which ( 50 and $150 \mathrm{msec}$ ) seem too brief to permit a saccade toward the cue before the target appeared. However, the target remained visible until the subject's response. As a result, shifts in fixation toward the cue might still 
have influenced the efficiency of the patients' visual detection, even if these saccades began only after the target first appeared.

This criticism does not apply to Klein et al.'s (1987, Experiment 2) normal study, since they monitored eye position to ensure that central fixation was maintained. However, as in the Farah et al. (1989) study, the dependent measure was simple visual RT in most of their experiments. It has long been argued (e.g., Duncan, 1980; Shaw, 1980; Sperling, 1984) that spatial cuing effects on simple RT may reflect criterion shifts rather than genuine effects of attention upon perception. Subjects may simply reduce the amount of evidence required for deciding whether a target has occurred on the cued side, and possibly increase their criterion for the uncued side, thus resulting in different simple RTs for the two sides. More recent studies of unimodal visual orienting (Hawkins et al., 1990; Luck et al., 1994) have developed more sophisticated methods for ruling out such criterion accounts, but these methods have not been applied to cross-modal studies as yet.

Perhaps the simplest way to address a criterion account is to require a speeded choice response to the visual target instead of speeded detection. A lower or more risky criterion should result in faster but less accurate performance on the cued side. This argument led Klein et al. (1987, Experiment 5) to conduct a study in which subjects made a choice response (brief vs. long duration) for a visual target after an uninformative peripheral sound. They found significantly faster choice responses for visual targets on the side of the auditory cue, just as with the simple detection response. Unfortunately, this choice RT effect was offset by a reverse trend in the error data (i.e., less accurate performance on the cued side), leaving the possibility of criterion accounts quite open.

Given these uncertainties over the correct interpretation of previous studies, the present experiments further examined the possibility of audiovisual links in covert exogenous orienting, using an adaptation of the orthogonalcuing paradigm introduced by Spence and Driver (1994). In our first study, subjects judged the elevation (up vs. down) of randomly intermingled light or sound targets, regardless of their laterality or modality. These targets were each preceded by an uninformative cue sound on the same side $(50 \%$ of trials) or opposite side ( $50 \%$ of trials) as the subsequent target. The uninformative cues had an intermediate elevation and therefore could not bias the up/ down judgment for the targets by any response priming.

This method allows us to examine whether uninformative peripheral sounds can induce both auditory and visual covert orienting, to influence judgments of subsequent auditory and visual targets, respectively. Since the cue was of no strategic use, any effects it produced should be under stimulus control. Intramodal exogenous orienting should produce faster and/or more accurate responses to auditory targets on valid versus invalid trials. Crossmodal exogenous orienting should produce an analogous result for visual targets.

\section{EXPERIMENT 1}

\section{Method}

Subjects. Twenty subjects were recruited by advertisement to take part in this experiment. Three subjects were unable to perform the auditory elevation discrimination at above $60 \%$ correct, and so their sessions were not analyzed. Of the remaining subjects ( $10 \mathrm{men}$ and 7 women), 13 were right-handed, 3 left-handed, and one ambidextrous by self-report. The mean age for subjects was 26 years, with a range of $20-40$ years. The subjects in this and all subsequent experiments were naive as to the purpose of the experiments and reported normal vision and hearing.

Apparatus and Materials. All our studies were conducted in a darkened, soundproof booth $(178 \times 122 \times 91 \mathrm{~cm})$ with a background luminance of $0.12 \mathrm{~cd} / \mathrm{m}^{2}$. Subjects were seated at a table, facing straight ahead with head movement precluded by an adjustable chinrest with cheek pads. A red LED was placed on a wall of the booth, $53 \mathrm{~cm}$ in front of the subject at eye level, to serve as a fixation point. The auditory cues were presented via either of two oval loudspeaker cones $(12.7 \times 7.6 \mathrm{~cm}, 8-\Omega, 20$-W, Radio Spares part No. RS 245-304) mounted on the same wall and located at ear level, $48^{\circ}$ from fixation (see Figure 1 for a schematic view of the experimental setup, seen from behind the subject's head).

The auditory targets were created by a white-noise generator, and were presented from any one of four additional loudspeaker cones of the same type as those used for the cues, located on the same wall. Two target loudspeaker cones were placed on either side of the subject, each arranged $23.5 \mathrm{~cm}$ above or below a cue loudspeaker. The visual target events were produced by the illumination of one of four red LEDs, with a luminance of $64.3 \mathrm{~cd} / \mathrm{m}^{2}$, each placed directly outside one of the four target loudspeakers, aligned with the center of the loudspeaker cone (see Figure 1). Following Spence and Driver (1994), the auditory cue event consisted of a $2000-\mathrm{Hz}$ pure tone presented for $100 \mathrm{msec}$ at $82 \mathrm{~dB}(\mathrm{~A})$, as measured from the subject's ear position. These cue sounds were designed to be unlocalizable in elevation (as explained in the Discussion) yet localizable in azimuth. The target sounds consisted of five $20-\mathrm{msec}$ bursts of white noise at $85 \mathrm{~dB}(\mathrm{~A})$, each separated by $10-\mathrm{msec}$ silent gaps. These target sounds were designed to be localizable in both

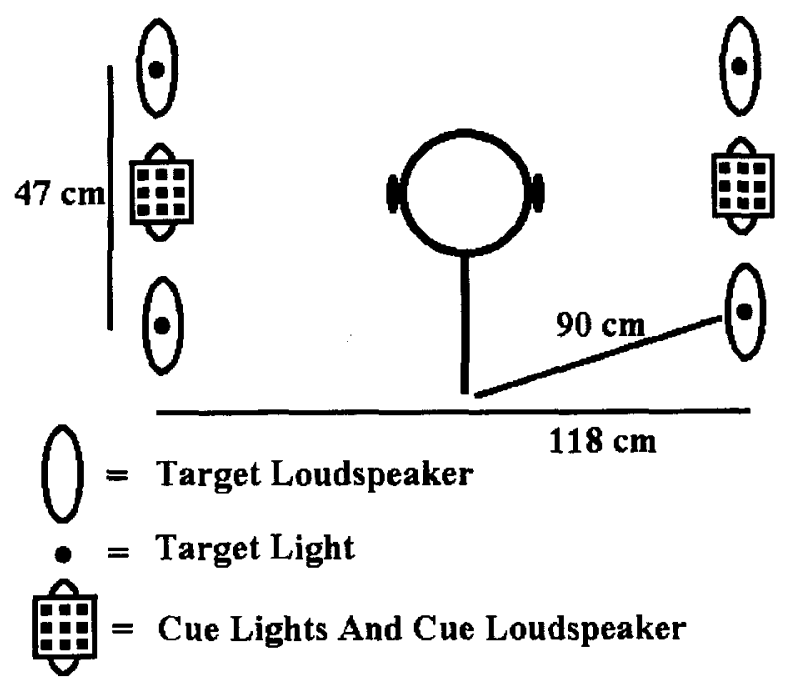

Figure 1. Schematic view of the position of the cue loudspeakers, target loudspeakers, target lights, and cue lights, as seen from behind the subject's head. The two grids of cue lights were not present in Experiments 1 and 2 but replaced the cue loudspeakers in Experiments 3-6. 
azimuth and elevation (as considered further in the Discussion). The visual targets consisted of the illumination of one of the four target LEDs for $140 \mathrm{msec}$.

The up-down decision for the targets required a discrimination of $28^{\circ}$ vertically. Subjects responded by pressing one of two microswitches attached to the tabletop in front of them, one immediately behind the other. RTs were measured in milliseconds from target onset by using an $82 \mathrm{C} 54$ interval-timer chip on one of the inputoutput cards (Blue Chip Technology parts DCM-16, ADC-42, and DOP-24) which interfaced to the loudspeakers and microswitches. Timing of the stimuli and responses was controlled by a Viglen $3 / 33$ microcomputer (IBM 386 compatible), using a program written in Turbo Pascal.

Design. The eight blocks had 144 trials each. There were four within-subject factors: target modality (auditory or visual), the side on which the target was presented (left or right), the stimulus onset asynchrony (SOA) between cue and subsequent target $(100,200$, and $700 \mathrm{msec}$ ), and whether the cue was on the same side as the target or on the opposite side (valid vs. invalid trials, respectively). These factors were crossed to yield 24 equiprobable conditions, each occurring six times pseudorandomly within each block.

Procedure. The fixation light was illuminated at the beginning of each trial and remained on until a response was made. The subjects were instructed to maintain fixation on this central red LED whenever it was illuminated (note that the shortest SOA was, in any case, too brief to permit saccades toward the side of the cue before the target terminated). After a random delay of $400-650 \mathrm{msec}$, the auditory cue, equally likely to be on the left or right, was presented for $100 \mathrm{msec}$. After a further delay (unpredictably 0,100 , or $600 \mathrm{msec}$, depending on SOA), the auditory or visual target was presented (target modality was unpredictable and equiprobable).

The subjects had to press the key farthest from them for an auditory or visual target from either of the upper target positions (regardless of side) and the nearest key for a target from either of the lower positions, responding as rapidly and accurately as possible with the index finger of either hand. The fixation light remained illuminated until a response was made. To give subjects feedback concerning their performance, the light was turned off immediately following a correct response, but flickered for $150 \mathrm{msec}$ following an erroneous response. Once extinguished, the red LED stayed off for $850 \mathrm{msec}$ before coming on again to signal the start of the next trial. The subjects were told that the auditory cues were completely uninformative, since visual and auditory targets were both equally likely to come from the side opposite to the sound as from the same side.

\section{Results}

In this experiment, the first block of trials was treated as practice and was therefore discarded. Incorrect responses, those immediately succeeding an incorrect response, and RTs below $150 \mathrm{msec}$ and above $1,500 \mathrm{msec}$ were also discarded from the RT analysis. The latter latency criteria removed less than $1 \%$ of trials from the ex- periment. The intersubject means of subjects' median RTs (after these exclusions), together with the corresponding error rates, are shown in Table 1, separately for each condition and target side, and in Figure 2, where the data are pooled across target side.

A four-way within-subject analysis of variance (ANOVA) on the median RTs had the factors of target modality, target side, validity, and SOA. This found a main effect of target modality $[F(1,16)=25.5, p=.0001]$, with subjects responding faster to visual targets (a mean of $431 \mathrm{msec}$ ) than to auditory targets $(516 \mathrm{msec})$. There was also a significant effect of validity $[F(1,16)=38.0$, $p<.0001]$, with subjects responding faster on valid trials. These two factors interacted $[F(1,16)=15.2, p=.001]$ presumably because subjects exhibited a larger validity effect in response to visual targets (mean advantage of $24 \mathrm{msec}$ for valid over invalid trials) than to auditory targets (mean advantage of $10 \mathrm{msec}$ for valid trials). That is, the validity effect was actually more substantial for the cross-modal orienting case than for the intramodal case.

There was a significant effect of SOA $[F(2,32)=3.7$, $p=.04]$, with subjects being slowest to respond at the shortest SOA (the conventional "alerting" effect; see Niemi \& Näätänen, 1981). There was also an interaction between validity and SOA $[F(2,32)=15.2, p<.0001]$, because the validity effect disappeared at the longer intervals for both modalities. There was no main effect of target side $[F(1,16)=.3$, n.s.]. The three-way interaction between modality, validity, and SOA was significant $[F(2,32)=3.9, p=.03]$. Pairwise comparisons $(t$ tests) revealed that the validity effect was significant at both the 100 - and 200-msec SOA for visual targets (a mean advantage for valid over invalid targets of 33 and $42 \mathrm{msec}$, respectively, both $p \mathrm{~s}<.01$ ), while for auditory targets it was significant only at the $100-\mathrm{msec}$ SOA (mean valid advantage of $24 \mathrm{msec}, p<.01$ ), with the advantage at the 200 -msec SOA being just a nonsignificant 6 -msec trend.

The modality $\times$ side $\times$ SOA interaction also reached significance $[F(2,32)=5.0, p=.01]$. Although we have no interpretation for this unpredicted interaction, $t$ tests revealed that subjects responded more rapidly to auditory targets presented from the left than to those presented from the right at the 100- and 200-msec SOAs (both $p$ s < .01 ), whereas, for visual targets, responses were more rapid on the right at the $200-\mathrm{msec}$ SOA $(p<.01)$. None of the other interactions in the ANOVA on RTs were significant.

Table 1

Mean Reaction Times (RTs; in Milliseconds) and Percentages of Errors for Auditory and Visual Targets Presented From the Left and Right in Experiment 1

\begin{tabular}{|c|c|c|c|c|c|c|c|c|c|}
\hline \multirow{3}{*}{\multicolumn{2}{|c|}{ SOA* }} & \multicolumn{4}{|c|}{ Auditory } & \multicolumn{4}{|c|}{ Visual } \\
\hline & & \multicolumn{2}{|c|}{ Left } & \multicolumn{2}{|c|}{ Right } & \multicolumn{2}{|c|}{ Left } & \multicolumn{2}{|c|}{ Right } \\
\hline & & RT & $\%$ & RT & $\%$ & RT & $\%$ & RT & $\%$ \\
\hline \multirow[t]{2}{*}{$100 \mathrm{msec}$} & Valid & 503 & 15.1 & 529 & 18.0 & 426 & 1.6 & 422 & 3.1 \\
\hline & Invalid & 538 & 15.8 & 543 & 20.6 & 458 & 2.9 & 456 & 3.5 \\
\hline \multirow[t]{2}{*}{$200 \mathrm{msec}$} & Valid & 491 & 13.2 & 522 & 19.7 & 415 & 2.5 & 397 & 3.4 \\
\hline & Invalid & 500 & 13.6 & 526 & 19.7 & 452 & 4.4 & 445 & 3.4 \\
\hline \multirow{2}{*}{$700 \mathrm{msec}:$} & Valid & 512 & 12.2 & 507 & 21.6 & 431 & 3.5 & 421 & 2.9 \\
\hline & Invalid & 501 & 14.2 & 520 & 18.9 & 424 & 3.1 & 426 & 4.5 \\
\hline
\end{tabular}

*Stimulus onset asynchrony. 


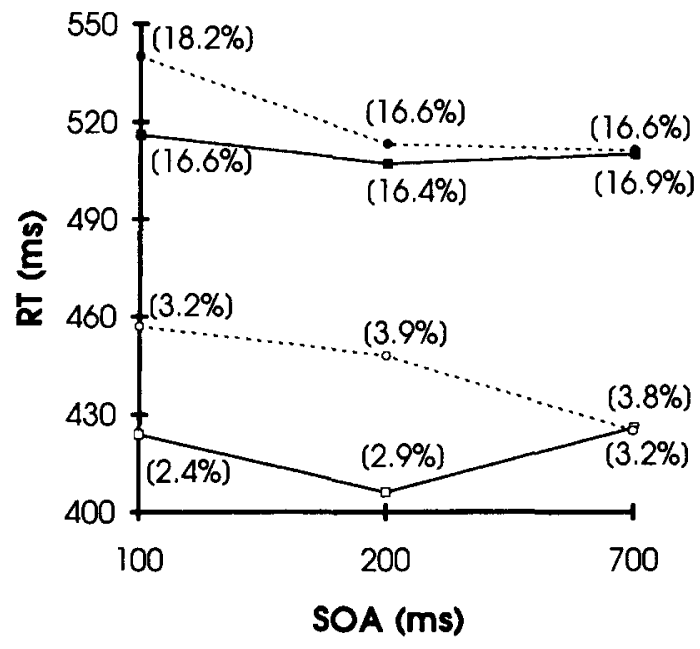

Figure 2. The intersubject means of median reaction time (RT) in Experiment 1, together with mean error rates, as a function of cue-target stimulus onset asynchrony (SOA) and showing the spatial effects of cuing for both auditory and visual targets. Open symbols represent visual trials; filled symbols represent auditory trials. Square symbols (continuous line) represent valid trials, where cue and target came from the same side, and circles (dotted line) show invalid trials, where cue and target were on opposite sides. Percentage error rates for each condition are given in brackets closest to the corresponding RT point.

An equivalent ANOVA on the error data revealed a significant effect of modality $[F(1,16)=18.9, p=.0005]$, with subjects making more errors to auditory targets (mean of $16.9 \%$ ) than to visual targets (mean of $3.2 \%$ ). There was also a main effect of side $[F(1,16)=5.2, p=$ $.04]$, with subjects making more errors when the target was presented from the right (mean of $11.6 \%$ ) than when it was presented from the left (mean of $8.5 \%$ ). Subjects made numerically more errors on invalid trials (mean of $10.4 \%$ ) than on valid trials (mean of $9.7 \%$ ). Although this trend for a main effect of validity was nonsignificant $[F(1,16)=2.1, p=.17]$, it does mean that the significant advantages for valid trials in RT cannot be due to speed-accuracy tradeoffs. None of the other effects or interactions were significant.

\section{Discussion}

Visual elevation judgments were faster and more accurate for targets that appeared shortly after an uninformative sound cue on the same rather than opposite side. This result suggests that an uninformative peripheral sound leads to exogenous visual orienting. Thus, a cross-modal cuing effect was observed. In addition, auditory elevation judgments were more efficient at short SOAs on the side of the cue, replicating the previous findings of Spence and Driver (1994, Experiments 1 and 2) for intramodal auditory exogenous orienting. Consistent with previous studies of exogenous orienting within just vision (e.g., Posner \& Cohen, 1984; Rafal et al., 1991) or within just hearing (Spence \& Driver, 1994), the present facilitatory cuing effects were short-lived for both auditory and vi- sual targets, being found only at short SOAs following the uninformative cue.

Our cross-modal results extend the previous observations of Klein et al. (1987) and Farah et al. (1989), while side-stepping the methodological criticisms that can be raised for those studies. Since the spatial dimension that had to be judged for the targets in our task (i.e., elevation) was orthogonal to the lateral dimension along which cue location varied, the present cuing effects cannot be attributed to response priming by the cue (cf. Bédard et al., 1993; Bernstein \& Edelstein, 1971; Rhodes, 1987; Simon \& Craft, 1970; Ward, 1994). Since a choice response, rather than a detection response, was employed, criterion shifts do not offer a natural explanation for the present cuing effects either.

Instead, these results suggest that exogenous orienting to an uninformative sound affects the localization of visual and auditory events, with more efficient discrimination of positions on the cued side than on the uncued side. This accords with recent conclusions from attentional research using paradigms other than the cuing technique (e.g., the study of illusory conjunctions or visual search; Cohen \& Ivry, 1989, 1991). Such research has suggested that spatial resolution is greater within an attended region, at least for the case of vision. The present results extend these suggestions by demonstrating that the effect on visual resolution can be elicited by auditory cues, and that analogous effects can be found within hearing.

Regarding our auditory findings, a reviewer was concerned that the high overall error rate in auditory localization (mean of $16.9 \%$ errors) might compromise interpretation of the auditory RT data. In particular, he suggested that the presence or absence of RT cuing effects might depend on the overall level of accuracy. To examine this, we conducted a further analysis of the auditory RT data, splitting our subjects into two equal groups by means of their overall error rate for auditory targets. The high-error group comprised 8 subjects with a mean error rate of $26.9 \%$; the low-error group comprised 8 subjects with a mean error rate of $6.1 \%$. A subsequent mixed ANOVA on the auditory RT data had the betweensubjects factor of error group, and the within-subjects factors of validity, modality, side, and SOA. This analysis found no main effect of error group $[F(1,14)=.5$, n.s.]. Moreover, error group did not interact with any of the other factors [for error group $\times$ modality, $F(1,14)=1.6$, $p=.23$; for error group $\times$ modality $\times \operatorname{SOA}, F(2,28)=$ $2.4, p=.11$; and for error group $\times$ validity $\times$ SOA, $F(2,28)=1.8, p=.19 ; F<1$ for all other interactions]. Subjects within both the low- and the high-error-rate groups showed mean valid advantages in auditory RT at the short SOA (mean invalid-valid effect of $31 \mathrm{msec}$ for the low-error-rate group and $18 \mathrm{msec}$ for the high-errorrate group). Likewise, both groups showed a trend for more errors on invalid than on valid trials. Thus, the intramodal cuing effect on auditory RTs was fairly consistent, regardless of the overall error rate in the more difficult auditory task. 
We have attributed the advantage for valid trials at short SOAs in both modalities to exogenous covert orienting. However, alternative nonattentional accounts must be considered. The subjects may have judged the elevation of the target relative to the cue (i.e., deciding whether the target sound was above or below the cue), rather than basing their judgments on the target's absolute elevation or its location relative to the other possible target elevation. Any such comparison with the cue could have been easier on valid trials, as the cue might provide a local landmark for the relative judgment when on the same side as the subsequent target. The subjects might even have based their judgments on some percept of apparent motion from the cue to the target, although this seems unlikely given their substantial physical difference (see Strybel, Witty, \& Perrott, 1992).

In fact, we had specifically used the $2000-\mathrm{Hz}$ puretone cues in an effort to avoid these apparent-motion or local-landmark strategies for the elevation discrimination. While the elevation of pulsed white noise (such as our targets) is relatively easy to judge, previous psychophysical studies have found that high-frequency pure tones (such as our cues) are impossible to judge in elevation (Roffler \& Butler, 1968), even though their lateral position can be resolved quite accurately. Thus, while our high-frequency cues should be capable of orienting attention laterally, they should be useless as landmarks for any relative-elevation judgments or as inputs to a verticalmotion detector, since their elevations should be effectively unknown.

Of course, these arguments depend on extrapolation from prior studies on localizing pure tones (e.g., Roffler $\&$ Butler, 1968). Rather than relying on this alone, we ran a control study to confirm that elevation judgments for the white-noise targets could not be based on relative judgments, or on motion perception, involving the elevation of the pure-tone cue.

\section{EXPERIMENT 2}

In this control study, the white-noise "targets" were now always presented at a constant intermediate elevation (since the ability to judge their elevation is not at issue) from one of the two loudspeaker cones previously used for the presentation of the lateral cues in Experiment 1 . These white noise stimuli were preceded by a $2000-\mathrm{Hz}$ "cue" which was now equally likely to come from any of the four loudspeakers previously used for targets (i.e., from up or down on the left or right). The new task was to make a judgment of whether the "cue-target" sequence within each trial went down in elevation or up in elevation.

Note that if subjects in Experiment 1 had adopted either of the strategies that could produce a nonattentional cuing effect, this new task would effectively be the same as the previous task. Since the white noise now had a fixed elevation, the required discrimination could no longer be based on its position alone. However, in terms of the el- evation of the white noise relative to the cue, the discrimination was analogous to that in Experiment 1. That is, the pure tone and the subsequent white noise were always $14^{\circ}$ apart in elevation, with the white noise either above or below the pure tone and with the two stimuli appearing on the same or opposite side, analogously to valid and invalid trials in the previous experiment. Thus, subjects should be able to perform the new task if they were able to do any of the following: (1) judge the absolute elevation of the pure tone; (2) judge the difference between its elevation and that of a subsequent white noise $14^{\circ}$ above or below, on the same or opposite side; or (3) discriminate the upward versus downward direction of any weak apparent-motion signal that may be provided by the sequence of a pure tone followed by a white noise $14^{\circ}$ above or below. On the other hand, if we are correct in assuming that our high-frequency cues cannot be localized in elevation, neither relative judgments nor apparent motion should be available for the cue-target sequence, and thus the new task should prove impossible.

\section{Method}

Subjects. Ten subjects ( 6 men and 4 women) participated in this control study. Their mean age was 27 years, with a range of $21-42$ years. All except 1 of the subjects were right-handed. Six "experienced" subjects had participated in an earlier experiment requiring them to localize a white-noise target in elevation, just as in Experiment 1 , for at least 300 trials. They had all achieved at least $68 \%$ accuracy on this task (with 3 reaching $98 \%$ correct), and were thus just as competent with the cues and targets as any of the subjects in Experiment 1 . The remaining four "inexperienced" subjects had not encountered the experimental stimuli before.

Apparatus and Materials. The apparatus was identical to that in Experiment 1. The auditory stimuli were also the same, except that the pure-tone "cue" sounds were now presented from any one of the four loudspeaker cones previously used for targets, while the subsequent white-noise "targets" were presented from either of the two loudspeakers, with intermediate elevation, which were previously used for cues.

Design and Procedure. There were two blocks of 96 trials. Each trial consisted of the presentation of a pure-tone "cue," followed immediately (as for the 100-msec SOA in Experiment 1, which had found intramodal cuing) by a "target" white noise. The tones and white noise were equally likely to occur on either side of fixation and on the same or opposite side. The subjects were instructed to press the farther button if the cue-target sequence appeared to shift upward (or equivalently, if the first "tone" in the sequence seemed to have been presented from below the subsequent white noise or "rattle"), and to press the nearer button if the sequence appeared to shift downward (or the first tone appeared to be presented from above). The subjects were required to make a response within $2 \mathrm{sec}$ of target onset, but otherwise accuracy was now stressed rather than rapid responding.

\section{Results}

The average percentage of correct responses is shown in Table 2 separately for the 6 experienced and 4 inexperienced subjects and for trials where the pure tone was on the same ("valid") or opposite ("invalid") side as the subsequent white noise. Of these trials, $6.6 \%$ were removed due to subjects' RTs' being below $150 \mathrm{msec}$ or over 2,000 msec. The following comparisons were ex- 
Table 2

Mean Percentage of Correct Responses for the Auditory Apparent Motion Discrimination in Experiment 2

\begin{tabular}{ccc} 
Subjects & $\begin{array}{c}\text { Same Side } \\
\text { (Valid) }\end{array}$ & $\begin{array}{c}\text { Different Side } \\
\text { (Invalid) }\end{array}$ \\
\hline Experienced & $53.8 \%$ & $54.2 \%$ \\
Inexperienced & $55.1 \%$ & $54.3 \%$ \\
\hline
\end{tabular}

amined in a chi-square test, but none reached significance at the .05 level. Neither group of subjects performed above chance for either the valid or the invalid trials, and there was no difference between the groups. Moreover, there was no difference between the number of correct responses made to valid versus invalid trials for either group.

\section{Discussion}

The results of this control experiment confirmed that subjects are incapable of reliably discriminating the elevation of our pure-tone cues. They cannot use them as a landmark for deciding whether an immediately following white noise is higher or lower in elevation than the cue; nor can they gain any impression of vertical apparent motion between the pure tone and the subsequent white noise. Neither experienced nor inexperienced subjects performed above chance in any condition. Moreover, there was no difference in accuracy for trials where the pure tone appeared on the same side as the immediately following white noise (analogous to valid trials at the 100msec SOA in Experiment 1) versus on the opposite side (analogous to the invalid trials at the $100-\mathrm{msec}$ SOA in Experiment 1). Thus, the validity effects for auditory targets at this SOA in Experiment 1 can be unambiguously attributed to exogenous covert orienting toward the side of the cue, rather than to the use of local-landmark or apparent-motion strategies, both of which are found to be impossible in the present study due to our use of a $2000-\mathrm{Hz}$ pure tone as the cue.

This confirmation that the cues cannot be localized in elevation means that the cross-modal effect in Experiment 1 (from auditory cues to visual targets) can also be unambiguously attributed to covert orienting. One possible interpretation of this cross-modal result would be that a supramodal orienting system is drawn to the location of the auditory cue, thus producing validity effects for both auditory targets and visual targets. Farah et al. (1989) have proposed just such a supramodal system for orienting to uninformative peripheral events, and have suggested that its substrate lies in the parietal lobe. If the supramodal hypothesis is correct, the reverse cross-modal influence should also apply in the control of exogenous covert orienting. That is, an uninformative visual event should induce an exogenous shift in auditory covert orienting, provided it is sufficiently salient to attract visual orienting.

Previous evidence on this specific question is inconclusive. Buchtel and Butter (1988) reported that spatially informative peripheral light cues, which were $80 \%$ valid about the side of the forthcoming auditory target, produced no validity effects on auditory detection latencies. They concluded that auditory attention cannot be drawn by visual events. However, detection responses may be an insensitive measure for the distribution of auditory attention (see Spence \& Driver, 1994), so Buchtel and Butter's null result might be attributed to the measure they used rather than to the absence of any cross-modal orienting. More recently, Ward (1994) examined whether uninformative visual events lead to exogenous orienting that affects auditory targets, and reported a positive result. However, he used a left/right localization task for targets appearing after cues on the left or right, and thus his validity effects might be attributable to response priming rather than to attentional shifts, as discussed earlier.

Given the equivocality of these previous results, our next experiment examined whether salient peripheral visual events (the sudden onset of a grid of 9 turbo LEDs) can lead to exogenous orienting in audition or vision, as measured by performance in our elevation task. On the basis of many previous studies demonstrating shifts of visual attention to uninformative visual cues (e.g., Posner, 1980), we expected that our visual targets would show validity effects determined by the visual cue. Specifically, we anticipated that valid trials would show an advantage over invalid trials at short SOAs. The more novel question was whether the visual cues would show a similar effect on auditory targets. Such a cross-modal effect would be predicted by any interpretation of the auditory-to-visual effect from Experiment 1 in terms of a strictly supramodal orienting system (e.g., Farah et al., 1989). On the other hand, it is logically possible that audiovisual links in covert orienting may apply in only one direction, with auditory events eliciting visual orienting but not vice versa. If so, it would be inappropriate to characterize exogenous orienting as entirely supramodal.

\section{EXPERIMENT 3}

\section{Method}

Nineteen new subjects took part in this experiment. Three were unable to make the auditory up-down discrimination at above $60 \%$ correct and so were removed from the analysis. Of the remaining 5 men and 11 women, 1 subject was left-handed and 1 was ambidextrous by self-report. The mean age for subjects was 21 years, ranging from 19 to 25 .

The apparatus, materials, design, and procedure were exactly as in Experiment 1, except that visual rather than auditory cues were now presented via either of two sets of nine yellow LEDs, each set arranged in a $3 \times 3$ square configuration at a distance of $90 \mathrm{~cm}$ from the subject on either side of fixation and mounted on the same wall as the red fixation LED (in the position where the cue loudspeakers had previously been; see Figure 1). These two grids of yellow LEDs were located at ear level, and each grid subtended a visual angle of $4.1^{\circ}$ at an eccentricity of $48^{\circ}$ from fixation. The luminance of each LED was $41.4 \mathrm{~cd} / \mathrm{m}^{2}$. A visual cue was presented on one side by briefly illuminating all nine LEDs in one of the grids. We used so many LEDs in an effort to ensure that the visual cues were sufficiently salient to produce covert orienting. 


\section{Results}

The intersubject means of subjects' median RTs, together with the corresponding error rates, are shown in Figure 3, pooled across target side.

A four-way within-subjects ANOVA on the median RT data (target side $X$ target modality $\times$ validity $\times$ SOA) found a main effect of target modality $[F(1,15)=$ $5.6, p=.03$ ], with subjects responding more rapidly to visual targets (mean of $501 \mathrm{msec}$ ) than to auditory targets $(531 \mathrm{msec})$. There was also a main effect of SOA $[F(2,30)=9.4, p=.0007]$, with subjects being slowest to respond at the shortest SOA. As in Experiment 1, this presumably reflects the conventional alerting effect. The effect of validity was also significant $[F(1,15)=6.0$, $p=.03$, with subjects responding more rapidly on valid trials than on invalid trials. Crucially, the modality $\times$ validity interaction was also significant $[F(1,15)=5.1$, $p=.04]$. A $t$ test revealed that the advantage for valid trials occurred only with visual targets (mean valid advantage for visual targets of $20 \mathrm{msec}$ across SOAs, $p<.01$ ).

The interaction between validity and SOA was significant $[F(2,30)=8.0, p=.0016]$, with subjects showing larger validity effects at the two shorter intervals than at the longest one (see Figure 3). Finally, the three-way interaction between modality, validity, and interval was also significant $[F(2,30)=3.4, p<.05]$. Comparisons of valid and invalid trials within the two target modalities by $t$ tests revealed that the only significant validity effects were for visual targets at the 100- and 200-msec SOAs (mean advantage for valid targets over invalid ones of 27 and $35 \mathrm{msec}$, respectively, both $p$ s $<.01$ ). No reliable validity effects were found for auditory targets at any SOA (the mean auditory validity effect at the $100-\mathrm{msec}$

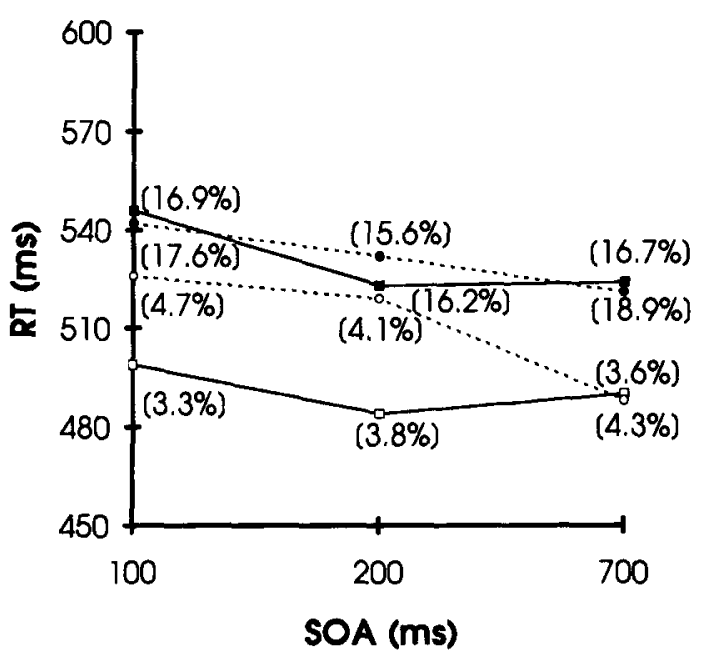

Figure 3. The intersubject means of median RT, together with mean error rates, as a function of cue-target stimulus onset asynchrony (SOA), for Experiment 3, showing the effects of cuing for both auditory and visual targets. Open symbols represent visual target trials; filled symbols represent auditory trials. Square symbols (continuous line) represent valid trials, and circles (dotted line) show invalid trials. Percentage error rates for each condition are given in brackets closest to the corresponding RT point.
SOA was $-3 \mathrm{msec}$, at the $200-\mathrm{msec} \mathrm{SOA},+8 \mathrm{msec}$, and at the $700-\mathrm{msec} \mathrm{SOA},-2 \mathrm{msec}$ ). Thus, while the visual cues produced orienting effects for visual targets, demonstrating the visibility and salience of these cues, they did not produce reliable cuing effects for auditory targets. None of the other effects or interactions were significant [for side $\times$ validity, $F(1,15)=2.6, p=.13$; for modality $\times$ side $\times$ SOA, $F(2,30)=1.1$, n.s.; and for the side $\times$ validity $\times$ SOA interaction, $F(2,30)=1.3, p=$ $.29 ; F<1$ for all other interactions].

An analogous ANOVA on the error data again revealed a main effect of target modality $[F(1,15)=25.3, p=$ $.0002]$, with subjects making more errors in response to auditory targets (mean of $17.0 \%$ errors) than to visual targets $(4.0 \%$ errors). None of the other effects or interactions were significant.

\section{Discussion}

These results suggest that our uninformative but salient visual cues (the sudden onset of a grid of nine yellow LEDs in a dark chamber) produce exogenous visual orienting, with the result that elevation discriminations are faster for visual targets on the side of the cue. This intramodal visual cuing effect is consistent with previous evidence that exogenous visual orienting facilitates a variety of visual discriminations (e.g., Briand \& Klein, 1986; Klein et al., 1992). As an aside, we note that attentional modulation of visual localization in particular, as here, might go some way to explaining the effects of attention on visual feature integration (e.g., Prinzmetal, Presti, \& Posner, 1986; Treisman \& Gelade, 1980), since conjunction tasks typically require finer grained localization than feature tasks (see Cohen \& Ivry, 1991).

The visual cues exerted no reliable validity effect on judgments for auditory targets. This apparently null effect for auditory targets following visual cues accords with Buchtel and Butter's (1988) proposal that visual onsets do not produce auditory orienting. Unlike their data, our findings cannot be attributed to the use of a simple detection measure that is insensitive to the distribution of auditory attention. The present null effect for auditory elevation discriminations contrasts with the findings of Experiment $l$ using the same task, where valid auditory trials were reliably faster than invalid trials immediately following an auditory cue. The present absence of reliable cuing for auditory targets seems problematic for the hypothesis of a single supramodal system for exogenous orienting (see Farah et al., 1989). The results for visual targets suggest that visual orienting was induced in the present experiment, and, on a strict supramodal hypothesis, auditory orienting must necessarily follow suit. However, it may be possible to offer a nonattentional explanation for the validity effect on visual targets. The supramodal hypothesis could then be defended by arguing that no orienting actually took place for any modality within Experiment 3.

The possible nonattentional accounts for the visual validity effect are similar to those for the auditory validity effect in Experiment 1, which we examined and dismissed 
in Experiment 2. Subjects in Experiment 3 may have based their visual elevation judgments on some comparison process that used the cue as a local landmark or on some vertical apparent-motion percept between cue and target. Either strategy might have been more efficient when cue and target were on the same side, thus producing the visual validity effect.

In Experiment 2, we were able to dismiss this account for auditory validity effects by showing that our auditory cues could not be localized in elevation. However, the present visual cues certainly could be localized in elevation, so the nonattentional explanations cannot be ruled out on this basis. Accordingly, we had to devise a modification of Experiment 3 specifically to exclude the nonattentional accounts for the intramodal visual cuing effects. In the next study, subjects again had to judge the elevation of auditory or visual targets after an uninformative visual cue on one side. However, the nature of this cue was now changed from a sudden onset to a sudden offset in illumination.

One or the other of two peripheral LEDs were used to provide the cue in the next study, each positioned where previously there had been a grid of nine LEDs. Crucially, these LEDs were now both illuminated continuously. A cue event took the form of one of these LEDs' being briefly extinguished (for $100 \mathrm{msec}$ ) and then returning to continuous illumination again. Since the LED that went off was illuminated again by the time any visual target appeared, no apparent motion could be produced between the cue event and a subsequent visual target, thus ruling out one of the nonattentional explanations for any validity effect. Equally, since both visual cues were illuminated by the time the target appeared, local landmarks for the elevation judgment were available on both sides, thus ruling out the other nonattentional explanation for any validity effect.

A further modification was that eye position was monitored in a subset of subjects, to confirm that any validity effects at longer SOAs ( $200 \mathrm{msec}$ and greater) were produced solely by covert attentional mechanisms. Finally, we attempted to render auditory performance less variable by making the auditory task easier. Subjects were now placed closer to the wall from which the stimuli were presented, increasing the effective angular separation of the stimuli. The separation between the upper and lower target positions on each side was now $40.1^{\circ}$ rather than the previous $28^{\circ}$. In addition, the loudspeaker cones were enclosed in cabinets to reduce the influence of echoes.

We tried to make the auditory task easier in this way for two reasons. First, in the cuing experiments so far, the auditory elevation discrimination was always harder than the visual discrimination. We wished to eliminate this difference in task difficulty between the modalities as a potential explanation for any apparent asymmetries in cross-modal attentional links. Second, and crucially, no reliable cuing effects for auditory targets after visual cues were found in Experiment 3. However, establishing any null hypothesis (e.g., that vision does not cue audition) via null results is invariably problematic, as one can always question whether a positive result would be found under other circumstances. Frick (1995) has recently argued that the null hypothesis can be accepted under some circumstances, provided that confidence intervals for the null result are sufficiently narrow, and that a "good effort" is made to secure a positive result instead by available methods. Unfortunately, the confidence intervals for the null cuing effects with auditory targets after visual cues in Experiment 3 were, in fact, quite broad due to the variability of auditory performance.

Specifically, the mean valid advantage in auditory RT at the 100 -msec SOA was $-3 \mathrm{msec}$, but the $95 \%$ confidence intervals locate this effect only between -21 and $+15 \mathrm{msec}$. Similarly, at the $200-\mathrm{msec}$ SOA, the mean validity effect was $8 \mathrm{msec}$, with $p(-9 \mathrm{msec}<\mu<26 \mathrm{msec})=$ 95. Finally, at the $700-\mathrm{msec}$ SOA, the mean effect was $-2 \mathrm{msec}$, with $p(-25 \mathrm{msec}<\mu<20 \mathrm{msec})=.95$. Thus, while no reliable validity effects were found for auditory targets after visual cues in the data sample of Experiment 3, the confidence intervals for possible population effects were quite broad. Hence, one aim of making the auditory task easier in the new study was to achieve much narrower confidence intervals on any validity effects for auditory targets after visual cues. Subsequent experiments in this paper have a similar aim, and together constitute the "good effort" to find a positive effect which Frick (1995) requires before any null hypothesis can be accepted.

\section{EXPERIMENT 4}

The primary purpose of this study was to replicate Experiment 3 , but using brief visual offsets as the lateral cue rather than brief visual onsets. We predicted that, as before, these visual cues would induce visual orienting but not auditory orienting. The predicted validity effect for visual targets could not be explained by any apparentmotion or local-landmark strategies for the elevation judgment, given our use of offset cues. The predicted null effect for auditory targets should have narrower confidence intervals, if the minor changes to the auditory task succeed in making it easier and thus less variable. Finally, the introduction of eye-movement monitoring should exclude any role for overt orienting at longer SOAs.

\section{Method}

Fourteen subjects ( 10 women and 4 men) took part in this experiment, and all except 1 were right-handed. The mean age for subjects was 23 years, with a range of 19-28. One subject had taken part in a previous experiment (Experiment 2). We increased our cutoff for including a subject's data from the $60 \%$ accuracy level used in Experiments 1 and 3 to at least $75 \%$ correct overall (and likewise in the subsequent experiments). We did so because the auditory discrimination task was now easier, and also in an effort to reduce variability and thus the confidence intervals surrounding any null auditory effects.

The apparatus, materials, design, and procedure were as for the previous experiment, with the following exceptions. Subjects' eyes were now only $42 \mathrm{~cm}$ from the fixation light. Thus, the columns of loudspeakers were laterally $52^{\circ}$ from fixation. The target loud- 
speakers were placed $25 \mathrm{~cm}$ above and below the midline on either side, resulting in an elevation discrimination for the targets of $40.1^{\circ}$. The previous grids of nine LEDs were replaced by a single LED on either side. These were both illuminated continuously throughout the experiment, except during a cue event, for which one of these two cue LEDs was extinguished for $100 \mathrm{msec}$.

The horizontal positions of the left eyes of 5 subjects were automatically monitored via an Eye Trac 210 monitor (Applied Science Laboratories), which relies on the infrared scleral reflectance method. This was connected to the microcomputer controlling the experiment via an interface board (Blue Chip Technology part ADC-42). Trials in which a potential eye movement was detected (note that blinks sometimes resulted in signals that were indistinguishable from actual eye-movement signals) were automatically excluded from the analyzed data for the 5 monitored subjects. The monitor was calibrated to provide a signal to the computer whenever an eye movement of $3.7^{\circ}$ or more was detected in the period from $250 \mathrm{msec}$ after the illumination of the central fixation LED until initiation of the manual choice response. (This was the smallest signal we could reliably detect across subjects; but recall that the lateral cues and targets were at least $52^{\circ}$ from central fixation.) The eye monitor was recalibrated to confirm true straight-ahead at the beginning of every block, and also during a block if fixation ever appeared to drift from the calibrated center point.

\section{Results}

Less than $3 \%$ of trials were removed due to the monitored subjects' moving their eyes (or blinking, which sometimes caused a similar eye-movement signal from the monitor). The intersubject means of subjects' median RTs, together with the corresponding error rates, are shown in Table 3 separately for each condition, target side, and subject group, and also in Figure 4, where the data are pooled across target side and subject group. (Note that, for this figure, each subject contributes equally to the depicted means, rather than each of the differently sized eyemovement groups' contributing equally.)

A five-way mixed ANOVA was carried out on the RT data. The between-subject factor was whether eye move- ments were monitored, and the four within-subject factors were target side, target modality, validity of the offset cue, and the interval (SOA) between this offset and the subsequent target. There was a main effect of whether eye movements were monitored $[F(1,12)=9.8, p=$ $.009]$, with subjects responding more slowly when this was the case. There was also a highly significant main effect of target modality $[F(1,12)=31.6, p=.0001]$, with subjects now responding more rapidly to auditory targets (mean of $450 \mathrm{msec}$ ) than to visual targets $(489 \mathrm{msec}$ ). Thus, we were successful in making the auditory task easier. The subjects responded more rapidly on valid trials than on invalid trials $[F(1,12)=19.8, p=.0008]$. There was a main effect of SOA $[F(2,24)=17.4, p<.0001]$, with subjects being slowest to respond at the shortest SOA, presumably reflecting the conventional alerting effect. Crucially, the modality $\times$ validity interaction was again significant $[F(1,12)=6.2, p=.03]$. Pairwise comparisons ( $t$ tests) revealed that the advantage for valid trials occurred only for visual targets (mean of $12 \mathrm{msec}$ across all SOAs, $p<.01$; for auditory targets, the mean effect was 1 msec across all SOAs, n.s.).

The modality $\times$ SOA interaction was significant $[F(2,24)=3.9, p=.03]$, with response latencies decreasing more for visual than for auditory targets as the SOA increased. The three-way interaction between modality, validity, and SOA was also significant $[F(2,24)=3.5$, $p<.05]$. Pairwise $t$ test comparisons of valid and invalid trials within the two target modalities revealed that the only significant validity effects were for visual targets at the 100- and 200-msec SOAs (mean advantage for valid over invalid targets of $13 \mathrm{msec}, p<.05$, at $100-\mathrm{msec} \mathrm{SOA}$, and $22 \mathrm{msec}, p<.01$, at the 200-msec SOA). No reliable validity effects were found for auditory targets at any SOA, but confidence intervals were nevertheless calculated on the null effects [the mean auditory validity ef-

Table 3

Mean Reaction Times (RTs; in Milliseconds) and Percentages of Errors for Auditory and Visual Targets Presented From the Left and Right, and Separated by Whether Eye Movements Were Monitored, in Experiment 4

\begin{tabular}{|c|c|c|c|c|c|c|c|c|}
\hline \multirow[b]{3}{*}{ SOA* } & \multicolumn{4}{|c|}{ Auditory } & \multicolumn{4}{|c|}{ Visual } \\
\hline & \multicolumn{2}{|c|}{ Left } & \multicolumn{2}{|c|}{ Right } & \multicolumn{2}{|c|}{ Left } & \multicolumn{2}{|c|}{ Right } \\
\hline & RT & $\%$ & RT & $\%$ & RT & $\%$ & RT & $\%$ \\
\hline \multicolumn{9}{|c|}{ Eye Movement Monitored $(n=5)$} \\
\hline 100 msec: Valid & 509 & 6.6 & 505 & 3.4 & 531 & 1.0 & 542 & 2.0 \\
\hline Invalid & 507 & 4.2 & 486 & 2.4 & 551 & 1.8 & 574 & 3.0 \\
\hline 200 msec: Valid & 504 & 5.0 & 493 & 5.4 & 525 & 0.0 & 519 & 1.0 \\
\hline Invalid & 491 & 5.8 & 488 & 3.6 & 544 & 2.8 & 550 & 2.4 \\
\hline 700 msec: Valid & 483 & 5.8 & 467 & 3.4 & 501 & 3.2 & 521 & 5.4 \\
\hline Invalid & 486 & 2.4 & 485 & 3.8 & 520 & 3.8 & 523 & 5.0 \\
\hline \multicolumn{9}{|c|}{ Eye Movement Not Monitored $(n=9)$} \\
\hline 100 msec: Valid & 405 & 2.9 & 412 & 3.1 & 458 & 2.8 & 466 & 3.7 \\
\hline Invalid & 416 & 3.7 & 407 & 3.1 & 461 & 3.6 & 463 & 4.1 \\
\hline 200 msec: Valid & 406 & 2.8 & 408 & 3.1 & 438 & 0.8 & 436 & 3.3 \\
\hline Invalid & 422 & 4.8 & 411 & 5.4 & 458 & 5.9 & 457 & 2.9 \\
\hline 700 msec: Valid & 409 & 4.2 & 400 & 5.6 & 427 & 2.3 & 432 & 2.8 \\
\hline Invalid & 404 & 4.9 & 404 & 4.0 & 423 & 2.8 & 418 & 3.7 \\
\hline
\end{tabular}

*Stimulus onset asynchrony. 


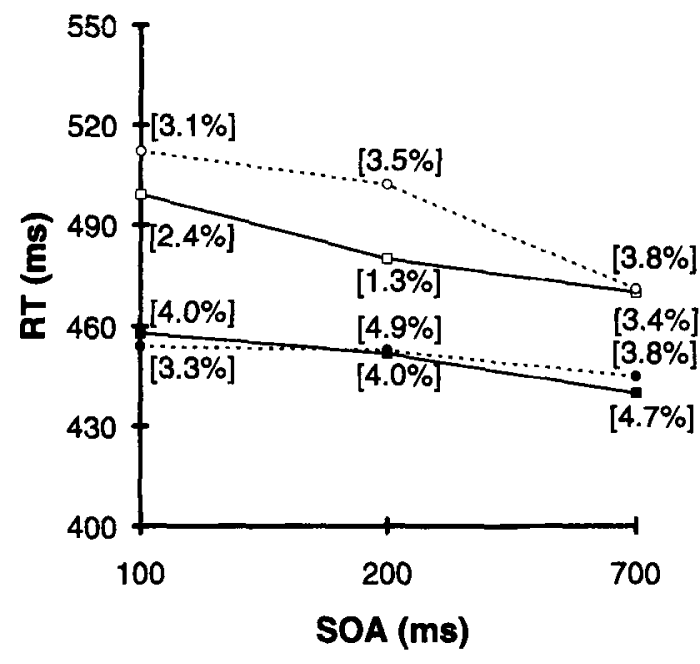

Figure 4. The intersubject means of median RT, together with mean error rates, as a function of cue-target stimulus onset asynchrony (SOA), for Experiment 4, showing the effects of cuing for both auditory and visual targets. Open symbols represent visual target trials; filled symbols represent auditory trials. Square symbols (continuous line) represent valid trials, and circles (dotted line) show invalid trials. Percentage error rates for each condition are given in brackets closest to the corresponding $R T$ point.

fect at the 100-msec SOA was $0 \mathrm{msec}, p(-10 \mathrm{msec}<\mu<$ $11 \mathrm{msec})=.95$; at the $200-\mathrm{msec} \mathrm{SOA}$, there was a mean effect of $3 \mathrm{msec}, p(-6 \mathrm{msec}<\mu<12 \mathrm{msec})=.95$; and at the $700-\mathrm{msec}$ SOA, there was a mean effect of $7 \mathrm{msec}$, $p(-3 \mathrm{msec}<\mu<17 \mathrm{msec})=.95]$. Thus, while the visual cues produced orienting effects for visual targets, thus demonstrating the visibility and salience of the offset cues, they did not produce any reliable cuing effects for auditory targets, replicating the null cross-modal results of Experiment 3 with somewhat narrower confidence intervals.

The three-way eye movement $\times$ modality $\times$ validity interaction was also significant $[F(1,12)=6.8, p=.02]$. This arose because the validity effect for visual targets was greater when eye movements were monitored (mean invalid minus valid difference of $20 \mathrm{msec}$ across all SOAs) than when they were not monitored (mean effect of only $4 \mathrm{msec}$ when pooled across all SOAs). While we have no account for this unpredicted interaction, it does underline the point that the visual validity effect cannot be attributed to overt orienting, because, if anything, this effect was larger in the group of subjects with eyes monitored. None of the other effects or interactions were significant.

An analogous five-way mixed ANOVA on the error data revealed only a significant interaction between eye monitoring, modality, and SOA $[F(2,24)=10.3, p=$ $.0006]$. This was because subjects whose eye movements were monitored made more errors on auditory trials at $100-\mathrm{msec}$ SOA, but more visual errors at the longest SOA, whereas this pattern was reversed for the subjects whose eye positions were not monitored. None of the other effects or interactions were significant.

\section{Discussion}

The results of Experiment 4 replicate those of the previous experiment, while addressing a number of methodological concerns. Visual elevation discriminations were again faster on the side of the visual cue. In the present study, this cue was a brief offset in one of two otherwise continuous peripheral lights. Hence the visual validity effect cannot reflect apparent motion between the cue and subsequent visual target or the availability of a visible landmark on just the cued side, as such landmarks were clearly available on both sides when the target appeared. We can therefore conclude that the intramodal visual validity effects reflect exogenous covert orienting to the uninformative offset, resulting in an advantage for visual elevation judgments on the cued side shortly after the cue. The visual validity effect at the 100 -msec SOA emerges too rapidly to be explained by overt eye movements taking place before target offset. Similarly, the visual validity effect at the 200-msec SOA can now also be attributed to purely covert mechanisms, since it was found even in the group of subjects for whom eye position was monitored (who, if anything, showed a larger visual validity effect).

A strong supramodal orienting hypothesis would predict that whenever visual covert orienting shifts toward one side, auditory orienting should follow. The present results apparently falsify such a prediction. Although there was clear evidence for visual covert orienting toward the uninformative visual offset, this cue had no reliable effect on auditory judgments. This null cross-modal result replicates the findings of Experiment 3, in the context of unequivocal visual orienting, and in a situation where the auditory task was now at least as easy as the visual task, making a direct comparison of the modalities more appropriate.

Although no reliable validity effects were found in either Experiment 3 or Experiment 4 for auditory discriminations following a visual cue, it remains possible that a small cross-modal influence of this kind does exist, but that we simply lacked the precision to detect it. In particular, inspection of the confidence intervals reveals that a small validity effect (up to 11 or $12 \mathrm{msec}$ at the two shorter SOAs) might actually have existed, yet remained unreliable due to noise in the auditory data. We therefore attempted to reduce the size of the confidence intervals on any auditory validity effects still further in the next experiment. Experiment 5 essentially repeated the design and methods of Experiments 3 and 4, except that only auditory targets were now presented. This enabled us to run twice as many auditory elevation-discrimination trials per subject in order to increase power.

To provide the "good effort" at producing a positive result that Frick (1995) requires before any null hypothesis can be accepted, the next study actually made two attempts at identifying any effect from visual cues upon auditory targets. For one group of subjects, auditory targets followed onset visual cues, just like those used in Ex- 
periment 3 . For the other group, auditory targets followed offset visual cues, just as in Experiment 4 . By comparing these two groups, we could again examine whether the offset and onset visual cues had similar effects, as already suggested by the comparison of Experiments 3 and 4 . In this way, we could rule out local-landmark or apparentmotion explanations for any cuing effects.

We did not monitor eye movements, since exogenous cuing effects typically emerge at cue-target SOAs which are too brief to permit saccades, and in any case, we no longer anticipated any cuing effects. The targets were now always auditory, and followed visual cues. Both Experiment 3 and Experiment 4 had shown that there were no reliable cross-modal cuing effects from vision upon audition, and we expected to replicate this null outcome once more. As it turned out, our expectation was not fulfilled at the longer cue-target SOAs.

\section{EXPERIMENT 5}

\section{Method}

Twenty-seven new subjects ( 8 men and 19 women) were recruited by advertisement to participate in the experiment. All except 2 were right-handed. One subject was unable to perform the auditory task at above $75 \%$ correct, and so that session was not analyzed. The mean age of the remaining subjects was 22 years, with a range of 17-34. The apparatus, materials, design, and procedure were as in Experiment 4, with the exception that now only auditory targets were presented, and that the grid visual cues from Experiment 3 were used in one group of subjects. For this onset group $(n=16)$, the visual cue comprised the sudden illumination of a grid of nine LEDs on one side, exactly as in Experiment 3. For the remaining 10 subjects, the offset group, the cuing event was the brief offset and subsequent reillumination of a single LED on one side, with the LEDs on both sides otherwise being continuously illuminated, just as in Experiment 4.

\section{Results}

The first block of trials was treated as practice and therefore discarded. Fewer than $1 \%$ of the trials were removed due to RTs falling outside the range of $150-1,500 \mathrm{msec}$. The intersubject means of subjects' median RTs, together with the corresponding error rates, are shown in Table 4 separately for each condition and target side, and also pooled across target side.
The median RT data were subjected to a mixed ANOVA, with the between-subjects factor of cue (onset vs. offset) and three within-subjects factors (side $\times$ validity $\times$ SOA). This analysis revealed a main effect of cue $[F(1,24)=$ $5.4, p=.03]$, with subjects responding more rapidly following a visual offset cue than following an onset cue. To our surprise, the effect of validity was also significant $[F(1,24)=8.3, p=.008]$, with subjects responding more rapidly on valid trials than on invalid trials overall. Furthermore, the interaction between validity and side was also significant $[F(1,24)=4.4, p<.05]$. Pairwise comparisons ( $t$ tests) revealed that the overall effect of validity was larger for targets presented on the left (mean invalid minus valid difference of $10 \mathrm{msec}, p<.01$ ) than for targets presented on the right $(M=2 \mathrm{msec}, \mathrm{n} . \mathrm{s}$. $)$.

For completeness, we looked more closely at the unexpected overall validity effect by conducting pairwise comparisons ( $t$ tests) of valid and invalid conditions at the various SOAs. These found reliable validity effects only at the longer SOAs [the mean invalid minus valid difference at $100 \mathrm{msec}$ SOA was only $2 \mathrm{msec}$, n.s., $p(-6 \mathrm{msec}<$ $\mu<8 \mathrm{msec})=.95$; at $200 \mathrm{msec}$, the mean effect was $8 \mathrm{msec}, p<.05, p(2 \mathrm{msec}<\mu<14 \mathrm{msec})=.95$; and at $700 \mathrm{msec}$, the mean effect was $9 \mathrm{msec}, p<.01, p(1 \mathrm{msec}<$ $\mu<17 \mathrm{msec})=.95]$. None of the other effects or interactions in the RT ANOVA reached significance.

An equivalent ANOVA on the error data revealed a significant effect of SOA $[F(2,48)=4.8, p=.01]$, with error rates decreasing as the SOA increased. None of the other effects or interactions reached significance for errors.

\section{Discussion}

All targets were now auditory following uninformative visual cues. The two types of visual cue (offset or onset) produced similar effects on auditory discrimination. In contrast to the null cross-modal effects in Experiments 3 and 4, both types of visual cue now had a small but reliable effect on performance in the auditory localization task (although this effect varied in an unexpected manner with target side). Overall, subjects made the up-down judgment slightly faster for auditory targets on the same side as the visual cue than for auditory targets appearing on the opposite side. The paired comparisons

Table 4

Mean Reaction Times (RTs; in Milliseconds) and Percentages of Errors for Left and Right Auditory Targets, Separated by Cue Type, Plus Averaged Across Target Side and Cue Type in Experiment 5

\begin{tabular}{|c|c|c|c|c|c|c|c|c|c|c|}
\hline \multirow[b]{3}{*}{ SOA* } & \multicolumn{4}{|c|}{ Cue Type: Offset } & \multicolumn{4}{|c|}{ Cue Type: Onset } & & \\
\hline & \multicolumn{2}{|c|}{ Left } & \multicolumn{2}{|c|}{ Right } & \multicolumn{2}{|c|}{ Left } & \multicolumn{2}{|c|}{ Right } & \multicolumn{2}{|c|}{ Averages } \\
\hline & RT & $\%$ & RT & $\%$ & RT & $\%$ & RT & $\%$ & RT & $\%$ \\
\hline 100 msec: Valid & 391 & 5.9 & 380 & 4.0 & 467 & 6.1 & 472 & 8.0 & 427 & 6.0 \\
\hline Invalid & 392 & 6.6 & 376 & 5.5 & 474 & 7.8 & 473 & 8.5 & 429 & 7.1 \\
\hline 200 msec: Valid & 380 & 5.7 & 376 & 4.4 & 464 & 6.7 & 466 & 8.9 & 421 & 6.4 \\
\hline Invalid & 400 & 6.1 & 373 & 4.9 & 470 & 6.3 & 474 & 7.7 & 429 & 6.2 \\
\hline 700 msec: Valid & 395 & 5.0 & 384 & 3.1 & 469 & 6.3 & 466 & 7.0 & 428 & 5.3 \\
\hline Invalid & 407 & 4.7 & 390 & 2.7 & 477 & 6.9 & 472 & 6.2 & 437 & 5.1 \\
\hline
\end{tabular}

*Stimulus onset asynchrony. 
found this validity effect to be reliable only at the two longer SOAs (200 and $700 \mathrm{msec}$ ).

This apparent time course for the present validity effect is unlike that typically seen in response to uninformative cues. The facilitatory effects of exogenous covert orienting normally peak and dissipate within $100-300 \mathrm{msec}$ of cue onset (e.g., Spence \& Driver, 1994; or see Experiments 1,3 , and 4 in the present series). ${ }^{1}$ By contrast, the present advantage for valid trials was reliable at the 700msec SOA, yet not at the 100-msec SOA, in the pairwise tests. Below we discuss two possible reasons for this atypical time course in the present visual-to-auditory cuing effect.

First, the effect may have been produced by saccades toward the cue, which we had neither measured nor prevented in this experiment, since no cuing effect had been anticipated. If so, the results may have no direct implications for covert orienting, but instead may simply reflect the direction of gaze, which has previously been found to influence hearing. On such an eye-movement account, the valid advantage should not emerge until a saccade was executed, and it might then remain for as long as fixation was directed toward one side. This could explain the apparently sluggish emergence of the effect (as compared with standard exogenous covert orienting effects) and its surprising longevity (still present at the 700 -msec SOA). The unexpected interaction of validity and target side in RTs, if real, could perhaps be due to some preference for making leftward rather than rightward saccades.

Of course, this saccade account is entirely post hoc. However, it seems consistent with the apparent time course of the present visual-to-auditory spatial cuing effect, and with previous data showing that auditory performance can be enhanced in the direction of gaze or by target-directed eye movements (Gopher, 1973; Jones \& Kabanoff, 1975; Platt \& Warren, 1972; Reisberg, Scheiber, \& Potemken, 1981). Most importantly, the eye-movement account was directly tested in our next study.

An alternative account for the atypical time course of the present visual-to-auditory effect was suggested during the review process. ${ }^{2}$ It may reflect the nature of the effective SOAs between auditory and visual events. A potential methodological problem when comparing the effects of auditory cues upon visual targets (as in Experiment 1), and vice versa (as in Experiments 3-5), is that physically equivalent SOAs between cues and targets may not be psychologically equivalent when the roles of cue and target are reversed across the modalities. One can argue that it takes longer to perceive the onset of visual events than of auditory events. For instance, simple detection latencies are typically $25-50 \mathrm{msec}$ shorter for auditory targets than for comparable visual events (Dinnerstein \& Zlotogura, 1968; Elliott, 1968; Rutschmann \& Link, 1964). Temporal order tasks can similarly reveal a benefit for auditory onsets over visual onsets, which can be as great as $70 \mathrm{msec}$ (Dinnerstein \& Zlotogura, 1968; although see Rutschmann \& Link, 1964). These findings suggest that the effective (or at least the phenomenal) SOA between a visual cue and a subsequent auditory target may actually be shorter than for unimodal cue-target combinations, which may in turn be shorter than for an auditory cue and subsequent visual target, when the physical SOA is held constant.

If correct, this argument would imply that exogenous covert orienting toward an auditory event may begin sooner than that following a comparable visual event. Moreover, exogenous covert orienting for an auditory target following a visual cue (i.e., the one effect which remains at issue) might emerge more slowly (i.e., only at physically longer SOAs) than for any other combination of cue and target. In principle, this might account for the atypical time course of the visual-to-auditory spatial cuing effect in Experiment 5, which was most reliable at the longest SOA $(700 \mathrm{msec})$. The late emergence for this effect is consistent with the prediction that visual-toauditory cuing effects should be particularly slow to emerge due to asychronies in the effective onset times for each modality.

Our final study tested the eye-movement and asynchrony accounts for the unexpected visual-to-auditory effect in Experiment 5. We again presented auditory targets after visual cues, but now required and monitored central fixation for one group of subjects. On the eyemovement account, we should find no spatial cuing effect within this group, since saccades were prevented. However, the group without fixation requirements should ideally replicate the findings of Experiment 5; that is, they should show a spatial cuing effect that emerges slowly, and that remains present even at the longest SOAs, due to eye movements toward the visual cue.

We also examined more closely the possible role of any asynchronies in effective onset times between visual and auditory events. One approach would attempt to equate the effective SOAs for visual cues and subsequent auditory targets against those for auditory cues and subsequent visual targets from our previous studies. However, one could always dispute which measure of temporal asynchrony would be most appropriate for such an exercise. Hence, it would be difficult to assert with any confidence that a particular set of SOAs was functionally equivalent, for the purposes of our cuing measure, across a reversal of cue and target modalities. Accordingly, we took the alternative approach of simply examining a very wide range of SOAs between a visual cue and a subsequent auditory target. This should provide us with further information on the time course of any visual-to-auditory spatial cuing effects. Ten different cue-target SOAs were implemented (100-550 msec in 50-msec steps). As it turned out, neighboring SOAs produced indistinguishable performance, so these neighbors were pooled to yield five different SOA groupings for the purposes of analysis.

On the account in terms of effective asynchronies between auditory and visual onsets, we should observe a spatial cuing effect from visual cues upon auditory tar- 
gets that emerges only at the longer SOAs, regardless of whether eye movements are monitored. On the saccade account, any such effects should be found only for subjects who are allowed to move their eyes, namely those for whom gaze is not monitored.

\section{EXPERIMENT 6}

\section{Method}

Thirty-four subjects were recruited by advertisement; 4 had already taken part in one of the previous experiments reported in this paper. The data from 3 subjects were not analyzed, as their performance did not exceed $75 \%$ correct. Of the 31 remaining subjects ( 19 men and 12 women), 26 were right-handed and 5 left-handed. Their mean age was 23 years, with a range of 15-43 years. The grids of nine LEDs from Experiments 3 and 5 were employed as visual cues. However, these were now used to present just offset cues, as introduced in Experiment 4, since this type of cue rules out apparent-motion or locallandmark explanations for any cuing effects. As in Experiment 4, visual cues on both sides were constantly illuminated, except when one was briefly extinguished for $100 \mathrm{msec}$ to provide an offset cuing event. Unlike Experiment 4, all nine LEDs in each grid were now employed in an effort to make the offset visual cues maximally salient.

The apparatus and materials were otherwise just as in Experiment 5 . Each subject performed 30 practice trials followed by seven blocks of 160 test trials each. There were three within-subject factors: side of target presentation (left or right), SOA between cue and target $(100,150,200,250,300,350,400,450,500$, or $550 \mathrm{msec})$, and cue validity. All levels on these factors were equally likely. The three factors were crossed to yield 40 equiprobable conditions, each occurring four times pseudorandomly within each block. Central fixation was required for one group of subjects $(n=20)$, whose eye position was monitored automatically, as in Experiment 4 . The procedure was otherwise exactly as for Experiment 5.

\section{Results}

The first short block of trials was treated as practice, and therefore discarded. Less than $1 \%$ of trials were removed due to RTs' falling outside the range of 150 $1,500 \mathrm{msec}$. Less than $4 \%$ of trials were removed due to excessive eye-movement signals in those subjects whose eye positions were monitored. The intersubject means of subjects' median RTs, together with the corresponding error rates, are shown for each group of subjects in Table 5, separately for each condition and target side, and also averaged across target side.

The median RT data were subjected to a mixed ANOVA, with the between-subject factors of whether eye movements were monitored, plus three within-subject factors (side $\times$ validity $\times$ SOA). Although 10 SOAs were used in the experiment, the analyses we present had only five levels of SOA, since neighboring SOAs were paired to yield the following five groupings: 100-150, 200-250, $300-350,400-450$, and $500-550 \mathrm{msec}$. This was done to simplify presentation, after an initial analysis found that neighboring SOAs produced indistinguishable results. The full ANOVA (with 10 SOA levels) produced the same pattern of results as the simplified ANOVA (with five SOAs levels) that we present. In this simplified analysis of RTs, there was a main effect of SOA $[F(4,116)=$ $3.6, p=.009]$, with subjects responding more slowly at the shortest SOA pairing than at any of the other intervals - that is, the usual alerting effect. There was also a main effect of validity $[F(1,29)=6.9, p=.01]$, with subjects responding more rapidly on valid trials overall.

Crucially, the interaction between eye monitoring and validity was also significant $[F(1,29)=5.5, p=.03]$, because there was no overall validity effect when eyemovements were monitored (mean invalid minus valid difference of $0 \mathrm{msec}$ ), but a mean valid advantage of $7 \mathrm{msec}$ for unmonitored subjects. None of the other main effects or interactions were significant.

In order to look at the eye-movement monitoring $x$ validity interaction more closely, we conducted threeway within-subject ANOVAs on the data for just the eyemonitored subjects and separately for just the unmonitored subjects. The analysis for eye-monitored subjects revealed no significant effects or interactions [for side, $F(1,19)=3.3, p=.08$; for SOA, $F(4,76)=2.3, p=.07$; and for side $\times$ SOA $\times$ validity, $F(4,76)=1.3, p=.26$; $F<1$ for all other effects and interactions]. In contrast, the analysis of the unmonitored subjects revealed a highly significant effect of validity $[F(1,10)=13.1, p<.005]$, with subjects responding more rapidly to valid trials (mean RT of $428 \mathrm{msec}$ ) than to invalid trials $(M=435 \mathrm{msec})$.

Table 5

Mean Reaction Times (RTs; in Milliseconds) and Percentages of Errors for Left and Right Auditory Targets Separated by Whether Eye Movements Were Monitored, Plus Averaged Across Target Side, in Experiment 6

\begin{tabular}{|c|c|c|c|c|c|c|c|c|c|c|c|c|}
\hline \multirow[b]{3}{*}{ SOA* } & \multicolumn{6}{|c|}{ Eye Movement Monitored $(n=20)$} & \multicolumn{6}{|c|}{ Eye Movement Not Monitored $(n=11)$} \\
\hline & \multicolumn{2}{|c|}{ Left } & \multicolumn{2}{|c|}{ Right } & \multicolumn{2}{|c|}{ Averages } & \multicolumn{2}{|c|}{ Left } & \multicolumn{2}{|c|}{ Right } & \multicolumn{2}{|c|}{ Averages } \\
\hline & RT & $\%$ & RT & $\%$ & RT & $\%$ & RT & $\%$ & RT & $\%$ & RT & $\%$ \\
\hline 100-150 msec: Valid & 444 & 7.2 & 430 & 5.2 & 437 & 6.2 & 443 & 3.8 & 438 & 4.7 & 441 & 4.2 \\
\hline Invalid & 442 & 6.8 & 434 & 5.4 & 438 & 6.1 & 444 & 5.2 & 431 & 3.7 & 437 & 4.5 \\
\hline $200-250$ msec: Valid & 434 & 7.0 & 428 & 5.7 & 431 & 6.3 & 434 & 4.6 & 416 & 4.9 & 425 & 4.7 \\
\hline Invalid & 438 & 7.9 & 418 & 7.2 & 428 & 7.6 & 437 & 5.0 & 435 & 5.3 & 436 & 5.2 \\
\hline 300-350 msec: Valid & 444 & 6.3 & 420 & 6.4 & 432 & 6.3 & 428 & 5.8 & 419 & 5.1 & 424 & 5.5 \\
\hline Invalid & 439 & 6.3 & 425 & 7.0 & 432 & 6.7 & 433 & 6.7 & 429 & 4.2 & 431 & 5.4 \\
\hline $400-450$ msec: Valid & 429 & 7.5 & 421 & 5.5 & 425 & 6.5 & 425 & 4.2 & 425 & 5.4 & 425 & 4.8 \\
\hline Invalid & 434 & 7.5 & 424 & 7.2 & 429 & 7.4 & 439 & 4.0 & 429 & 5.2 & 434 & 4.6 \\
\hline $500-550$ msec: Valid & 436 & 6.3 & 421 & 7.2 & 428 & 6.7 & 431 & 5.2 & 422 & 3.4 & 427 & 4.3 \\
\hline Invalid & 430 & 6.8 & 426 & 6.2 & 428 & 6.5 & 434 & 4.0 & 443 & 4.7 & 439 & 4.4 \\
\hline
\end{tabular}

*Stimulus onset asynchrony. 
The effect of SOA was also significant $[F(4,40)=3.1, p=$ .03 ], with subjects responding more rapidly at the longer intervals. None of the other effects or interactions were significant.

Pairwise comparisons ( $t$ tests) revealed that the effect of validity was not significant at any of the five SOA intervals in the eye-monitored group. The mean invalid minus invalid difference at the $100-150 \mathrm{msec}$ SOA was $1 \mathrm{msec}, p(-6 \mathrm{msec}<\mu<8 \mathrm{msec})=.95$; at the 200-250 msec SOA, the mean effect was $-3 \mathrm{msec}, p(-12 \mathrm{msec}<$ $\mu<7 \mathrm{msec})=.95$; at the $300-350 \mathrm{msec} \mathrm{SOA}$, it was $0 \mathrm{msec}, p(-9 \mathrm{msec}<\mu<10 \mathrm{msec})=.95$; at the $400-450$ msec SOA, it was $4 \mathrm{msec}, p(-5 \mathrm{msec}<\mu<13 \mathrm{msec})=$ .95; and at the 500-550 msec SOA, it was $0 \mathrm{msec}$, $p(-7 \mathrm{msec}<\mu<7 \mathrm{msec})=.95$. Thus, with eye movements monitored, the validity effects were consistently null across SOA, with relatively narrow confidence intervals.

In the unmonitored group, similar analysis revealed that the effect of validity was significant at two of the SOA intervals. The mean invalid minus invalid difference at the $100-150 \mathrm{msec}$ SOA was $-4 \mathrm{msec}, p>.05, p(-15 \mathrm{msec}<$ $\mu<8 \mathrm{msec})=.95$; at the $200-250 \mathrm{msec}$ SOA, the mean effect was $11 \mathrm{msec}, p<.05, p(2 \mathrm{msec}<\mu<20 \mathrm{msec})=$ .95 ; at the $300-350 \mathrm{msec} \mathrm{SOA}$, it was $7 \mathrm{msec}, p>.05$, $p(-2 \mathrm{msec}<\mu<17 \mathrm{msec})=.95$; at the $400-450 \mathrm{msec}$ SOA, it was $9 \mathrm{msec}, p>.05, p(-2 \mathrm{msec}<\mu<19 \mathrm{msec})=$ .95 ; and at the 500-550 msec SOA, it was $12 \mathrm{msec}, p<$ $.05, p(2 \mathrm{msec}<\mu<23 \mathrm{msec})=.95$.

An omnibus mixed ANOVA on the error rates found only one significant term; for the three-way interaction between eye monitoring, side, and SOA, $F(4,116)=2.7$, $p=.04$. While we have no interpretation for this result, we note that it was caused primarily by eye-monitored subjects making more mistakes for left targets at the two shortest SOA intervals, while unmonitored subjects tended to make more errors for left targets at the 300$350 \mathrm{msec}$ SOA. None of the other effects or interactions reached significance.

\section{Discussion}

The purpose of this experiment was to test the eyemovement and asynchrony accounts for the atypical time course of the visual-to-auditory cuing effect that was unexpectedly found in Experiment 5 (when eye movements were not prevented). The eye-movement account argues that this effect was due to saccades, and so should be eliminated when subjects' eyes are monitored to ensure central fixation throughout. The asynchrony account argues that auditory events have an effective onset sooner than visual events. Hence, physically short cue-target SOAs do not allow sufficient time for orienting to the visual cue prior to the effective onset of the auditory target. Only relatively long physical SOAs between a visual cue and a subsequent auditory target should act like the relatively short SOAs between events within a common modality that usually produce exogenous orienting effects. Hence, any visual-to-auditory spatial cuing effect should emerge only at relatively long physical SOAs; and this should apply regardless of whether eye movements are monitored.

The present results seem more consistent with the eyemovement account. The visual cues produced no reliable spatial cuing effects on auditory judgments for the group of subjects who had their eyes monitored to ensure that they maintained central fixation. The mean validity effect for this group was zero across a wide range of SOAs, and zero or very close to zero for each individual SOA. This finding replicates the null cross-modal cuing results for auditory targets reported in Experiments 3 and 4, but across a much greater range of SOAs and with narrower confidence intervals. This fits our null hypothesis that uninformative visual cues do not result in exogenous shifts of auditory attention, with the added caveat that this applies only under conditions in which overt orienting is prevented.

The null visual-to-auditory cuing effect when eyes were monitored arose even though the present visual cues can demonstrably produce intramodal visual orienting effects (Experiments 3 and 4) and can even influence auditory elevation judgments when eye movements are allowed (Experiment 5). The latter point was confirmed again in the present study. Although no visual-to-auditory cuing effects were found in the eye-monitored group, there were some validity effects in the unmonitored group, just as there were for the unmonitored subjects of Experiment 5 . Once again, these effects were relatively slow to emerge, and quite durable, reaching significance in the pairwise tests for the $200-250 \mathrm{msec}$ SOA and also at the longest SOA used, just as in Experiment 5 (along with trends toward a validity effect at all the intermediate SOAs).

We presume that these validity effects were produced by eye movements. This would accord with their complete absence in the eye-monitored group, which is not predicted by any account in terms of possible asynchronies alone. Possible differences in the effective onset times for different modalities remain a difficult methodological problem when comparing the time-course of any positive cross-modal results, while reversing which modality provides the cue and which the target. However, this complication does not undermine Experiment 6's finding that there were no such covert orienting effects from a visual cue upon auditory targets when eye movements were prevented. Crucially, this result held across a wide range of SOAs and extended to SOAs as great as $550 \mathrm{msec}$.

Whatever measure one uses, estimates of effective onset differences between auditory and visual events never exceed $100 \mathrm{msec}$ (Dinnerstein \& Zlotogura, 1968; Elliott, 1968; Rutschmann \& Link, 1964). Thus, at most, the asynchrony account might predict that visual-toauditory cuing effects should emerge $100 \mathrm{msec}$ later than intramodal cuing effects. Hence, our $100-$ to $550-\mathrm{msec}$ range of SOAs should have encompassed any covert orienting effects that could have been observed, since all such 
effects were found within a 100 - to 200 -msec SOA range for our unimodal and auditory-to-visual conditions in the preceding studies.

The point that any asynchrony in the effective onset times for vision and hearing is unlikely to exceed around $100 \mathrm{msec}$ also has implications for interpreting Experiment 5 . In that study, eye movements were not prevented, and we found a visual-to-auditory cuing effect which was most reliable at a physical SOA of $700 \mathrm{msec}$. The above considerations suggest that the effective cue-target SOA should have been at least $600 \mathrm{msec}$ for this condition, and at such an interval any advantage for the cued side has typically dissipated in exogenous covert orienting studies. Thus, our finding of visual-to-auditory cuing effects at such long cue-target SOAs (and only when eye movements are allowed) seems most parsimoniously explained by saccades toward the visual cue. These should continue to exert their effect for as long as gaze is maintained at the cued location. Hence, validity effects might be observed long after the cue when saccades are permitted.

Since the present paper is concerned with cross-modal links in covert orienting rather than in overt orienting, we shall not discuss the apparent effect of eye movements any further, nor seek to confirm it in more detail. For our purposes, the most important finding is the consistently null visual-to-auditory cuing effect in the eye-monitored groups. A further paper (Rorden \& Driver, 1996) directly addresses how saccade programming may influence auditory localization. For the moment, we make only the following observations about eye movements and auditory attention. First, our results demonstrate the importance of monitoring eye movements in spatial cuing studies, even when the task ostensibly concerns just auditory performance, since we found a different pattern in monitored and unmonitored groups. Second, the observation of an apparent eye-movement influence upon audition is consistent with some previous work (Gopher, 1973; Jones \& Kabanoff, 1975; Platt \& Warren, 1972; Reisberg et al., 1981 ) and with the time-course of the present visual-toauditory cuing effects when found. Third, the positive validity effects for the unmonitored group of Experiment 6 and for the subjects of Experiment 5 demonstrate that our auditory localization measure is, in principle, sufficiently sensitive to index a visual-to-auditory effect. This renders the null effect when eye movements are prevented all the more informative.

\section{GENERAL DISCUSSION}

Using variations on the orthogonal cuing procedure of Spence and Driver (1994), our experiments examined any audiovisual links within exogenous covert orienting. Experiment 1 used uninformative auditory cues prior to randomly intermingled auditory or visual targets. Elevation discriminations were faster on the cued side for targets in both modalities. Experiment 2 showed that this advantage for valid trials could not have been due to subjects' merely judging the elevation of targets relative to a cue on the same side, since the auditory cues that we used could not be localized in elevation, and did not produce any useful vertical apparent-motion signal in conjunction with the target.

In Experiment 3, salient but uninformative visual cues (the onset of a grid containing nine turbo LEDs in a darkened chamber) were followed unpredictably by auditory or visual targets. Visual elevation judgments were faster on the side of the cue. However, the visual cues had no reliable spatial cuing effect on auditory elevation judgments (although the confidence limits on the size of any auditory cuing effect were quite broad).

This finding of visual covert orienting without any apparent auditory orienting was fully replicated with narrower confidence intervals in our next study, which was similar to Experiment 3 except that the visual cues were now produced by temporarily extinguishing one of two peripheral LEDs which were otherwise continuously illuminated. This modification allowed us to rule out nonattentional explanations for the visual validity effect in terms of apparent motion or of local landmarking by the visual cue. The results of Experiment 4 demonstrated unequivocal visual covert orienting to the cued side in the apparent absence of auditory orienting to that side. This undermines purely supramodal models of covert orienting (e.g., Farah et al., 1989) as they dictate that exogenous shifts in visual and auditory attention must always take place together. In Experiment 4, the auditory elevation discrimination was actually performed more efficiently than the visual task overall, whereas the reverse had applied in Experiment 3. It therefore seems that the null effect of visual cuing on auditory performance does not depend on the relative difficulty of the auditory task as compared with the visual task.

In Experiment 5, we attempted to replicate this null visual-to-auditory effect once again, while narrowing the confidence intervals on any positive effect still further by collecting twice as many auditory data from each subject. To our surprise, this experiment revealed a small, but significant, cuing effect at the 200 - and 700 -msec SOAs. However, since eye movements were not monitored in this study, it remained possible that rather than any covert shift of attention, it was overt orienting which may have caused the spatial cuing effects at the longer intervals. This would be consistent with the atypically prolonged time-course of the effect.

An alternative explanation would be that auditory events are perceived more rapidly than visual events. As a result, cue-target SOAs may need to be longer for spatial cuing to be observed when a visual cue precedes an auditory target, as compared with the reverse situation. However, even the highest estimates of asynchrony in the perception of auditory and visual events would have difficulty explaining a visual-to-auditory cuing effect at delays as prolonged as $700 \mathrm{msec}$. Nonetheless, our final study examined auditory performance at a much wider range of SOAs following a visual cue in order to provide further information on the time-course of any cuing effects.

This study was similar to Experiment 5, except for the wider range of SOAs and for the monitoring of eye move- 
ments in one group of subjects to ensure central fixation. These subjects showed absolutely no visual-to-auditory spatial cuing effects at any of 10 cue-target SOAs between 100 and $550 \mathrm{msec}$. By contrast, those subjects whose eye movements were not monitored showed a significant validity effect, which was reliable even at the longest SOAs. These results suggest that the visual-to-auditory cuing effects reported in Experiment 5, with their atypically prolonged time-course, may have been due to subjects making eye movements toward the cue, resulting in better auditory performance on valid trials when the auditory targets were presented in the direction of gaze. The complete absence of any such effect when eye movements were monitored is certainly consistent with this account.

We therefore propose that visual events do not induce covert auditory orienting when eye movements are prevented. Of course, it is methodologically very difficult to confirm such a null hypothesis, which must rely on null results. Frick (1995) recently argued that the null hypothesis should be accepted only when confidence intervals on the null finding are reasonably narrow, when the null result is in the context of some positive findings which ensure a suitable sensitivity, and when a "good effort" has been made to demonstrate a positive effect instead of the null effect that is found.

The present null effect of visual cues on auditory targets when saccades are prevented was replicated three times (Experiments 3 and 4, plus the eye-monitored subjects of Experiment 6), with narrower confidence intervals in each successive case. Moreover, in our efforts to demonstrate a visual-to-auditory cuing effect, we used a variety of salient visual cues (offsets and onsets of several kinds) and looked at a wide range of cue-target SOAs (see Experiment 6). Moreover, the consistently null effects were obtained in the context of several positive findings: for visual targets after a cue in either modality, for auditory targets after an auditory cue, and even after a visual cue when saccades were not prevented.

Finally, the null effects do not appear to be strategic in any way. For instance, visual-to-auditory cuing effects, with eye movements prevented, were absent regardless of whether target modality was predictable (Experiment 6) or not (Experiments 3 and 4); and thus regardless of whether the subjects were focused on a particular target modality in advance, to the possible exclusion of the cue modality. Taking all these factors into consideration, we appear to have satisfied Frick's (1995) various criteria for accepting the null hypothesis.

Nevertheless, even our narrowest confidence intervals (Experiment 6, eye-monitored subjects) do not allow us to assert that there is absolutely no visual-to-auditory spatial cuing effect-only that any such effect must be extremely small. Thus, the most conservative interpretation of our results might be for a weak asymmetry in crossmodal links, such that the influence of audition upon vision in covert spatial orienting is merely greater than the reverse influence. However, for the time being, we prefer the stronger claim that, in the absence of eye movements, vision has no influence on exogenous covert au- ditory orienting, if only because this stronger hypothesis is more readily falsifiable.

Two studies recently reported by Ward (1994) apparently pose an immediate challenge to this strong hypothesis, since they led him to postulate precisely the opposite asymmetry in cross-modal exogenous orienting! Ward's subjects made left-right localization responses for auditory targets in one experiment and for visual targets in the other. In both cases, the targets were preceded by cues that could occur in either modality, sometimes with a simultaneous auditory and visual cue. Single cues in each modality could independently appear to the left, to the right, in front of the subject, or not at all. The visual targets appeared $12^{\circ}$ from fixation, and the auditory targets $24^{\circ}$ from fixation. The cues appeared at these same eccentricities, or at fixation (in the case of audition, "central" cues were produced by eccentric stimulation on both sides simultaneously). Ward's major findings were that lateral visual cues affected both visual and auditory left-right localization responses. By contrast, lateral auditory cues affected only auditory left-right localization. Thus, visual cues affected judgments in both modalities, whereas auditory cues affected judgments only within audition. This aspect of the results is the direct opposite of what we found when eye movements were prevented.

However, several objections can be raised against Ward's (1994) study. For instance, he did not monitor eye movements. Moreover, his validity effects may simply reflect response priming, or spatial compatibility, rather than attentional shifts. As discussed earlier, a lateral cue should bias a left-right localization response, speeding this response to the target when ipsilateral to it. There are many precedents for such response priming in the literature (e.g., Bernstein \& Edelstein, 1971; Simon \& Craft, 1970; and many other variants on the "Simon" effect). Ward (1994) acknowledged this potential criticism, but argued against it as follows. He suggested that if response priming were the only factor behind his results, both auditory and visual cues should have produced validity effects for targets in either modality. However, auditory cues did not produce validity effects for visual targets in Ward's study. Given this null-validity effect, he argues that his positive validity effects cannot be due to response priming. Note that interpretation of the positive results in Ward's study thus hinges on interpretation of his single null result.

We would suggest that actually all Ward's (1994) findings might be explained by response priming, including the null result for visual targets following auditory cues. Recall that the lateral auditory events were twice as peripheral as the lateral visual events in this study. An auditory cue would therefore fall "outside" a visual target on the same side, whereas a visual cue would fall "inside" an auditory target on the same side. Thus, a left visual target would fall to the relative right after a valid left auditory cue. This rightward sequence might lead to the initial activation of a leftward response tendency by the cue being followed by some activation of a rightward response to the target. That is, a response-conflict situation 
might arise, similar to the case of an invalid right visual target following the same left sound cue. Thus, while response priming should lead to validity effects in most of Ward's conditions, it might not in the particular case of outer auditory cues followed by inner visual targets, just as he observed.

In fact, there are many precedents for this suggestion in the literature on spatial compatibility effects. For example, Umiltà and Nicoletti (1985) review a number of experiments (and present their own) to suggest that spatial compatibility effects arise in relative left-right terms, rather than in terms of absolute stimulus or effector locations. Moreover, Nicoletti and Umiltà (1989) specifically showed that left-right compatibility effects can arise relative to the current locus of covert attention. On our hypothesis, Ward's uninformative auditory cues should shift both auditory and visual exogenous attention to the cued locus (e.g., outer left). In this example, a valid visual target would fall in the inner left position, that is, to the right of the attended locus. It would thus be compatible with a right rather than left response (Nicoletti \& Umiltà, 1989), just as for an invalid visual target in the inner right location, on the other side of the subject, and so no validity effect would be expected for this condition on the basis of response priming and compatibility effects.

The thrust of our argument is that interpretation of Ward's (1994) positive validity findings depends on interpretation of his null effect for visual targets after auditory cues. Unfortunately, plausible alternative accounts can be found for this null result in terms of spatial compatibility and response-priming effects, in which case the positive findings may also be reduced to such effects. In any case, Ward's conclusion that auditory events do not produce visual orienting is at odds with our Experiment 1 , which found clear visual orienting following uninformative sound cues. This result is not susceptible to the objections that Ward raised for previous reports of visual orienting to sounds (Farah et al., 1989; Klein et al., 1987), namely atypical patterns of validity effects against cuetarget SOA or possible criterion shifts.

In sum, we do not think our strong hypothesis of a one-way dependence between auditory and visual exogenous covert orienting (with only the former affecting the latter) is falsified by Ward's (1994) results, as these can be attributed to response priming and spatial compatibility effects. On the contrary, the present Experiment 1 falsifies Ward's hypothesis of the opposite asymmetry, by demonstrating visual covert orienting to an uninformative sound! Of course, future results may similarly falsify our own asymmetry hypothesis, since the claim that visual events do not engage auditory exogenous orienting must by its very nature rest on null results. Note, however, that in contrast to Ward's findings, interpretation of our positive cross-modal findings concerning exogenous covert orienting (Experiment 1 ) does not rest on interpretation of our null findings (Experiments 3, 4, and 6). Moreover, many of our specific conclusions should stand even if our asymmetry hypothesis falls. We have demonstrated that uninformative sounds can produce ex- ogenous visual orienting. Moreover, we have demonstrated that this covert orienting influences visual localization. We have also demonstrated that covert visual orienting can take place in the apparent absence of corresponding auditory orienting, at least when eye movements are prevented. Finally, the results of Experiment 6, in particular, underline the importance of monitoring eye movements in spatial cuing studies, even when the target task is auditory. No such monitoring was implemented in Ward's (1994) cross-modal studies.

On the basis of the experiments reported here, and our literature review, we have hypothesized that visual covert orienting tends to accompany exogenous covert auditory orienting, whereas the reverse dependency does not apply when eye movements are prevented. Here we briefly consider possible reasons for this apparent asymmetry in audiovisual dependence. The suggestions are all somewhat speculative, but hopefully may guide future research.

Neumann, Van der Heijden, and Allport (1986) discussed possible differences between attention in audition and vision. As they noted, real-world auditory events tend to be intermittent and transient, as compared with more continuous visual events. Thus, it would make evolutionary sense to arrange any cross-modal dependence such that visual attention shifts toward auditory events, rather than vice versa, since events of interest are more likely to become inaudible but remain visible than they are to become invisible but remain audible. Unfortunately, this suggestion seems difficult to test empirically.

A further argument would suggest that any cross-modal links in covert orienting have developed from, or are closely related to, existing cross-modal links in overt orienting (see Klein et al., 1992; Rafal et al., 1991; Rizzolatti, Riggio, Dascola, \& Umiltà, 1987; Shepherd, Findlay, \& Hockey, 1986, for extensive discussions of the relationship between overt and covert orienting mechanisms). A number of authors have suggested that the primary function of auditory localization is to direct overt visual orienting (Aitkin, 1986; Hafter \& De Maio, 1975; Harrison \& Irving, 1966; Heffner \& Heffner, 1992a, 1992b; Perrott et al., 1990; Pumphrey, 1950). As noted in our introduction, the overt orienting reflex to sudden sounds is well documented in humans, and we depend largely on sounds for overt visual orienting to events outside the current field of view (e.g., behind the head). Moreover, we are primarily visual creatures (witness the amount of cortex dedicated to vision) and have finest acuity within this modality. Thus, it may be paramount for our nervous system to get the fovea (and/or visual attention) to the locus of interesting auditory events, rather than to get auditory attention to the locus of events that have already attracted gaze or visual attention.

Turning to other species, it is well documented that many animals can move just their eyes toward sudden sounds (e.g., King, 1993). However, we know of no comparable evidence that species with movable pinna ever shift just their ears to sudden visual events! Thus, the asymmetry that we have documented for covert orienting in humans may also exist for overt orienting in a number 
of species. Certainly, existing neuroscientific evidence indicates that electrical stimulation of auditory layers deep in the superior colliculus of the cat can induce spatiotopic saccades (see King, 1993). By contrast, stimulation of more superficial visual layers does not elicit spatiotopic pinna movements; stimulation at deeper sites, to simulate an auditory input, is apparently required for this (Stein \& Clamann, 1981).

Comparative anatomical studies also support the view that one of the primary functions of sound localization may be the control of overt visual orienting. Heffner and Heffner (1992a) find across a range of species that the acuity of sound localization in the horizontal plane correlates particularly strongly with the horizontal width of the field of best vision (roughly speaking, the extent to which the animal's retina has a fovea). They argue that the precision of auditory localization in any species depends on the precision required when overtly directing visual resources for the further examination of interesting sound sources. This might go some way to explaining an otherwise curious linear function (Harrison \& Irving, 1966; Irving \& Harrison, 1967) which describes, across species, the relationship between the number of cells in the nucleus of the sixth cranial nerve (a brainstem structure involved in saccades) and in the medial superior olivary nucleus (a brain-stem structure involved in auditory localization). The positive correlation between these two measures has been taken to suggest that, from their earliest stages, the auditory pathways are heavily committed to serving overt visual attention. Our findings suggest that this relationship between the modalities may also apply for the case of covert attention in humans.

Recent anatomical and neurophysiological evidence about the representation of auditory and visual space in the mammalian brain also provides a possible account for our observed asymmetry. This evidence reveals the existence of abundant spatiotopic visual "maps," from the retina onwards, which code visual spatial position independently of auditory information (Cowey, 1985). Attention could, in principle, be directed within these purely visual maps without any influence on audition. By contrast, the neuroscientific data show (King, 1993) that there may be no purely auditory maps of space (i.e., no spatiotopic auditory maps that are uninfluenced by vision). The only established spatiotopic map of auditory space (in the superior colliculus) interacts with vision, and the direction of attention within such a map should therefore influence vision as well as hearing. Thus, the existence of purely visual maps and the absence of any analogous purely auditory maps might explain the one-way dependence between the modalities that we have observed.

This general account can be illustrated for the specific case of the superior colliculus (SC). This subcortical structure provides a particularly relevant example for our argument, since it is known, on the basis of single-cell and lesion studies (Stein \& Meredith, 1993; King, 1993), to be involved in overt exogenous orienting to sights and sounds in a number of species. Moreover, it is also thought to provide a substrate for covert exogenous orienting, at least in the case of primates. Involvement in covert orienting is suggested by single-cell and lesion studies in behaving monkeys (e.g., Desimone, Wessinger, Thomas, \& Schneider, 1992; Wurtz, Goldberg, \& Robinson, 1982) and by behavioral studies of normal and braindamaged humans within the visual spatial cuing paradigm (Posner, Rafal, Choate, \& Vaughan, 1985; Rafal et al., 1991). Finally, Stein and Meredith (1993) review a wide range of evidence which suggests that the colliculus is also an important site for audiovisual interactions in the control of spatial orienting, such as the cross-modal influences examined in the present study.

Physiological studies in animals find that the three superficial layers of the SC are purely visual and spatiotopically organized (Sparks, 1988; Sparks \& HartwichYoung, 1989), providing one example of a visual map in which attention might be directed without any necessary influence on audition. By contrast, there is no clear neuroscientific evidence for any purely auditory map in which attention could be directed without influencing vision (King, 1993, p. 562). Cells throughout the primary auditory pathway are organized in a tonotopic rather than spatiotopic manner. Although some cells have been found with lateralized, purely auditory receptive fields in the inferior colliculus and in primary auditory cortex (Clarey, Barone, \& Imig, 1992), there is no suggestion of fine spatial tuning or spatiotopic organization within these areas. In fact, the only clear evidence for a map of "auditory" (but actually polymodal) space in the mammalian brain is within the SC, in the three deeper layers beneath the three superficial, purely visual layers that were discussed above.

A plethora of recent studies reveal that the twodimensional location of auditory targets is represented topographically within these deeper layers (e.g., see King, 1993, for a review; also Middlebrooks \& Knudsen, 1984; Palmer \& King, 1982; Tiao \& Blakemore, 1976). In addition to the topographic representation of sound azimuth along the rostrocaudal axis of the SC, this map also represents the elevation axis along its mediolateral extent (Annetts, Howse, Hutchings, \& King, 1987). However, the map in these deeper layers of the SC is actually multimodal rather than purely auditory (Stein \& Meredith, 1993). In addition to auditory inputs, there are visual and somatosensory inputs. The three modalities are mapped in approximate spatiotopic register and also in register with the motor maps in the deepest layers that are associated with overt orienting (Sparks, 1988; Stein, 1984).

Thus, the one clearly established "auditory" spatiotopic map in the mammalian brain, within the deeper layers of the SC, actually appears to be multimodal. Any shift of attention within this representation should therefore have implications for the other modalities, just as we have found for vision following covert shifts of exogenous auditory attention toward peripheral sounds in humans. The possible effect of eye movements upon auditory localization, which we inferred from Experiment 5 and the unmonitored subjects in Experiment 6, might 
also have their basis in the deeper layers of the SC, where cells concerned with auditory localization interact with those involved in saccades.

The dependence of the "auditory" map in the deeper layers of the SC upon the representations of visual space within the same structure is also highlighted by developmental studies of neurophysiology. These show in several species that the representation of auditory space in the deeper layers of the SC depends on experience, and can be manipulated by varying the visual environment (King \& Carlile, 1993; King, Hutchings, Moore, \& Blakemore, 1988; Knudsen \& Brainard, 1991; Knudsen, Esterly, \& du Lac, 1991; Withington, 1992). By contrast, the spatial organization of the superficial, purely visual layers of the SC is apparent at the earliest physiological recordings (King \& Carlile, 1993), and several manipulations of auditory experience are thought to have no influence on these visual maps (King, personal communication, April 29, 1994, reviewing a number of studies: Knudsen, Esterly, \& Knudsen, 1984; Withington-Wray, Binns, Dhanjal, Brickley, \& Keating, 1990). Thus, an asymmetrical relationship between the two modalities is also found developmentally.

In sum, the neuroscientific evidence suggests that there are several visual maps which are uninfluenced by audition, and within which purely unimodal orienting might therefore take place. One such visual map exists within the hypothesized substrate for exogenous spatial orienting in the superficial layers of the SC. By contrast, current evidence suggests that there are no purely auditory spatiotopic maps in this structure, or elsewhere. The only spatiotopic auditory map identified to date is in the deeper layers of the SC, which also represent visual space. If auditory space is represented only topographically within such multimodal maps, auditory orienting within these representations will necessitate corresponding visual orienting, as we have observed in our human behavioral data. Moreover, these deeper layers provide a possible substrate for the apparent interaction between eye movements and auditory localization suggested by Experiments 5 and 6 .

Relating our results to the existing neuroscientific data in this way is clearly somewhat speculative. Nevertheless, it does add further weight to our strong hypothesis that exogenous covert shifts of auditory attention must be accompanied by corresponding shifts of visual attention, while the reverse need not apply. As we have been at pains to point out, this proposed asymmetry is a falsifiable hypothesis, consistent with the existing evidence but open to disproof. However, as noted earlier, many of our more specific conclusions concerning exogenous covert orienting in vision and audition should stand regardless of the ultimate fate of our asymmetry hypothesis.

\section{REFERENCES}

AItKIN, L. (1986). The auditory midbrain. Clifton, NJ: Humana Press. Annetts, C. S. J., Howse, B. P. A., Hutchings, M. E., \& King, A. J.
(1987). A digitally controlled vertical loop system for the presentation of free-field auditory and visual stimuli. Journal of Physiology, 382, 21 P.

Bédard, M. A., El Massioui, F., Pillon, B., \& Nandrino, J. L. (1993). Time for reorienting of attention: A premotor hypothesis of the underlying mechanism. Neuropsychologia, 31, 241-249.

Bernstein, I. H., \& Edelstein, B. A. (1971). Effects of some variations in auditory input upon visual choice reaction time. Journal of Experimental Psychology, 87, 241-247.

BRIAND, K. A., \& KLEIN, R. M. (1986). Is Posner's "Beam" the same as Treisman's "Glue"?: On the relation between visual orienting and feature integration theory. Journal of Experimental Psychology: Human Perception \& Performance, 13, 228-241.

Brown, C. H., \& MAY, B. (1989). Sound localization and binaural processes. In M. Berkley \& W. Stebbins (Eds.), Comparative perception (pp. 247-284). New York: Wiley.

BuCHTEL, H. A., \& ButTER, C. M. (1988). Spatial attention shifts: Implications for the role of polysensory mechanisms. Neuropsychologia, 26, 499-509.

Clarey, J. C., Barone, P., \& IMIG, T. J. (1992). Physiology of thalamus and cortex. In A. N. Popper \& R. R. Fay (Eds.), The mammalian auditory pathway: Neurophysiology (pp. 232-334). New York: SpringerVerlag.

Clarkson, M. G., Swain, I. U., Clifton, R. K., \& Cohen, K. (1991). Newborns' head orientation toward trains of brief sounds. Journal of the Acoustical Society of Amcrica, 89, 2411-2420.

COHEN, A., \& IVRY, R. [B.] (1989). Illusory conjunctions inside and outside the focus of attention. Journal of Experimental Psychology: Human Perception \& Performance, 15, 650-663.

COHEN, A., \& IVRY, R. B. (1991). Density effects in conjunction search: Evidence for a coarse location mechanism of feature integration. Journal of Experimental Psychology: Human Perception \& Performance, 17, 891-901.

COWEY, A. (1985). Aspects of cortical organization related to selective impairments of visual perception: A tutorial review. In M. I. Posner \& O. S. M. Marin (Eds.), Attention and performance XI (pp. 41-62). Hillsdale, NJ: Erlbaum.

Desimone, R., Wessinger, M., Thomas, L., \& Schneider, W. (1992). Attentional control of visual perception: Cortical and subcortical mechanisms. Cold Harbor Symposia on Quantitative Biology, 55, 963-971.

Dinnerstein, A. J., \& Zlotogura, P. (1968). Intermodal perception of temporal order and motor skills: Effects of age. Perceptual \& Motor Skills, 26, 987-1000

Driver, J., \& SPENCE, C. J. (1994). Spatial synergies between auditory and visual attention. In C. Umiltà \& M. Moscovitch (Eds.), Attention and performance $X V$ : Conscious and nonconscious information processing (pp. 311-331). Cambridge, MA: MIT Press.

DUNCAN, J. (1980). The demonstration of capacity limitation. Cognitive Psychology, 12, 75-96.

EL.FNER, L. F., \& HowSE, W. R. (1987). Auditory localization in a free field using discrimination procedures. Journal of Auditory Research, 27, 1-14

El.lotT, R. (1968). Simple visual and simple auditory reaction time: A comparison. Psychonomic Science, 10, 335-336.

FaraH, M. J., Wong, A. B., Monheit, M. A., \& Morrow, L. A. (1989) Parietal lobe mechanisms of spatial attention: Modality-specific or supramodal? Neuropsychologia, 27, 461-470.

FrICK, R. W. (1995). Accepting the null hypothesis. Memory \& Cognition, 23, 132-138.

GoPHER, D. (1973). Eye-movement patterns in selective listening tasks of focused attention. Perception \& Psychophysics, 14, 259-264.

HAFTER, E. R., \& DE MAIO, J. (1975). Difference thresholds for interaural delay. Journal of the Acoustical Society of America, 57, 181-187.

HARRISON, J. M., \& IRVING, R. (1966). Visual and nonvisual auditory systems in mammals. Science, 154, 738-743.

Hawkins, H. L., Hillyard, S. A., Luck, S. J., Mouloua, M., DownING, C. J., \& WoOdWARD, D. P. (1990). Visual attention modulates signal detectability. Journal of Experimental Psychology: Human Perception \& Performance, 16, 802-811.

HefFner, R. S., \& HefFner, H. E. (1992a). Evolution of sound local- 
ization in mammals. In D. B. Webster, R. R. Fay, \& A. N. Popper (Eds.), The evolutionary biology of hearing (pp. 691-715). New York: Springer-Verlag.

HefFner, R. S., \& HefFner, H. E. (1992b). Visual factors in sound localization in mammals. Journal of Comparative Neurology, 317 , 219-232.

Hublet, C., Morais, J., \& Bertelson, P. (1976). Spatial constraints on focussed attention: Beyond the right side advantage. Perception, 5, 3-8.

Hublet, C., Morais, J., \& Bertelson, P. (1977). Spatial effects in speech perception in the absence of spatial competition. Perception, 6, $461-466$.

IRving, R., \& HaRrison, J. M. (1967). The superior olivary complex and audition: A comparative study. Journal of Comparative Neurology, 130, 77-86.

JONES, B., \& KABANOFF, B. (1975). Eye movements in auditory space perception. Perception \& Psychophysics, 17, 241-245.

JONIDES, J. (1981). Voluntary vs. automatic control over the mind's eye's movement. In J. Long \& A. [D.] Baddeley (Eds.), Attention and performance $I X$ (pp. 187-203). Hillsdale, NJ: Erlbaum.

KING, A J. (1993). A map of auditory space in the mammalian brain: Neural computation and development. Experimental Physiology, 78, 559-590.

KING, A. I., \& CARLILE, S. (1993). Changes induced in the representation of auditory space in the superior colliculus by rearing ferrets with binocular eyelid suture. Experimental Brain Research, 94, 444-455.

King, A. J., Hutchings, M. E., Moore, D. R., \& Blakemore, C. (1988). Developmental plasticity in the visual and auditory representations in the mammalian superior colliculus. Nature, 332, 73-76.

KLEIN, R. M. (1994). Perceptual-motor expectancies interact with covert visual orienting under conditions of endogenous but not exogenous control. Canadian Journal of Experimental Psychology, 48, 167-181.

Klein, R. M., Brennan, M., \& Gilani, A. (1987, November). Covert cross-modality orienting of attention in space. Paper presented at the annual meeting of the Psychonomic Society, Seattle.

Klein, R. M., Kingstone, A., \& Pontefract, A. (1992). Orienting of visual attention. In K. Rayner (Ed.), Eve movements and visual cognition: Scene perception and reading (pp. 46-65). New York: SpringerVerlag.

KNUDSEN, E. I., \& Brainard, M. S. (1991). Visual instruction of the neural map of auditory space in the developing optic tectum. Science, 253, 85-87.

Knudsen, E. I., Esterly, S. D., \& DU LaC, S. (1991). Stretched and upside-down maps of auditory space in the optic tectum of blindreared owls: Acoustic basis and behavioral correlates. Journal of Neuroscience, 11, 1727-1747.

Knudsen, E. I., Esterly, S. D., \& Knudsen, P. F. (1984). Monaural occlusion alters sound localization during a sensitive period in the barn owl. Journal of Neuroscience, 4, 1001-1011.

luck, S. J., Hillyard, S. A., Mouloua, M., Woldorf, M. G., Clark, V. P., \& HAWKINS, H. L. (1994). Effects of spatial cuing on luminance detectability: Psychophysical and electrophysiological evidence for early selection. Journal of Experimental Psychology: Human Perception \& Performance, 20, 887-904.

Mazzuchi, A., Cattelani, R., \& Umilì̀, C. (1983). Hemispheric prevalence in acoustical attention. Brain \& Cognition, 2, 1-11.

Middlebrooks, J. C., \& KNudSEN, E. I. (1984). A neural code for auditory space in the cat's superior colliculus. Journal of Neuroscience, 4, 2621-2634

MiLLS, A. W. (1958). On the minimum audible angle. Journal of the Acoustical Society of America, 32, 132-134.

Muir, D., \& FiELD, J. (1979). Newborn infants orient to sounds. Child Development, 50, 43I-436.

Müller, H. J., \& Rabbitr, P. M. A. (1989). Reflexive and voluntary orienting of visual attention: Time course of activation and resistance to interruption. Journal of Experimental Psychology: Human Perception \& Performance, 15, 315-330.

Neumann, O., Van der Heijden, A. H. C., \& Allport, D. A. (1986). Visual selective attention: Introductory remarks. Psychological Research, 48, 185-188.

Nicoletri, R., \& Umiltì, C. (1989). Splitting visual space with attention. Journal of Experimental Psychology: Human Perception \& Performance, 15, 164-169.
Niemi, P., \& NäÄtänen, R. (1981). Foreperiod and simple reaction time. Psychological Bulletin, 89, 133-162.

Palmer, A. R., \& King, A. J. (1982). The representation of auditory space in the mammalian superior colliculus, Nature, 299, 248-249.

Perrott, D. R., Saberi, K., Brown, K., \& Strybel, T. Z. (1990). Auditory psychomotor coordination and visual search performance. Perception \& Psychophysics, 48, 214-226.

Platt, B. B., \& WARREN, D. H. (1972). Auditory localization: The importance of eye movements and a textured visual environment. Perception \& Psychophysics, 12, 245-248.

PoSNer, M. I. (1978). Chronometric explorations of mind. Hillsdale, NJ: Erlbaum.

PosNer, M. I. (1980), Orienting of attention. Quarterly Journal of Experimental Psychology, 32, 3-25.

PoSNer, M. I., \& COHEN, Y. (1984). Components of visual orienting. In H. Bouma \& D. G. Bouwhuis (Eds.), Attention and performance X: Control of language processes (pp. 531-556). Hillsdale, NJ: Erlbaum.

Posner, M. I., Rafal, R. D., Choate, L., \& Vaughan, J. (1985). Inhibition of return: Neural basis and function. Cognitive Neuropsychology, 2, 211-228.

Prinzmetal, W., Presti, D. E., \& Posner, M. I. (1986). Does attention affect visual feature integration? Journal of Experimental Psychology: Human Perception \& Performance, 12, 361-369.

PumPhrey, R. J. (1950). Hearing. Symposium of the Society for Experimental Biology: Physiological Mechanisms in Animal Behavior, 4, 3-18.

Quinlan, P. T., \& Bailey, P. J. (1995). An examination of attentional control in the auditory modality: Further evidence for auditory orienting. Perception \& Psychophysics, 57, 614-628.

Rafal, R., HeniK, A., \& SMITH, J. (1991). Extrageniculate contributions to reflex visual orienting in normal humans: A temporal hemifield advantage. Journal of Cognitive Neuroscience, 3, 322-328.

Reisberg, D., Scheiber, R., \& POTEMKen, L. (1981). Eye position and the control of auditory attention. Journal of Experimental Psychology: Human Perception \& Performance, 7, 318-323.

RHODEs, G. (1987). Auditory attention and the representation of spatial information. Perception \& Psychophysics, 42, 1-14.

Rizzolatti, G., Rigglo, L., Dascola, I., \& UMiltà, C. (1987). Reorienting attention across the horizontal and vertical meridians: Evidence in favor of a premotor theory of attention. Neuropsychologia, 25, $31-40$.

Roffler, S. K., \& BUtler, R. A. (1968). Factors that influence the localization of sound in the vertical plane. Journal of the Acoustical Society of America, 43, 1255-1259.

RORDEN, C., \& DRIVER, J. (1996). Does saccadic preparation affect auditory attention? Manuscript in preparation.

Rutschmann, J., \& Link, R. (1964). Perception of temporal order of stimuli differing in sense mode and simple reaction time. Perceptual \& Motor Skills, 18, 345-352.

Scharf, B., Quigley, S., Aoki, C., Peachey, N., \& Reeves, A. (1987). Focused auditory attention and frequency selectivity. Perception \& Psychophysics, 42, 215-223.

SHAW, M. L. (1980). Identifying attentional and decision-making components in information processing. In R. S. Nickerson (Ed.), Attention and performance VIII (pp. 277-296). Hillsdale, NJ: Erlbaum.

Shepherd, M., Findlay, J. M., \& Hockey, R. J. (1986). The relationship between eye movements and spatial attention. Quarterly Journal of Experimental Psychology, 38A, 475-491.

Simon, J. R., Acosta, E., JR., \& Mewaldt, S. P. (1975). Effect of locus of warning tone on auditory choice reaction time. Memory \& Cognition, 3, 167-170.

SimON, J. R., \& CRAFT, J. L. (1970). Effects of an irrelevant auditory stimulus on visual choice reaction time. Journal of Experimental Psychology, 86, 272-274.

Sokolov, E. N. (1963). Perception and the conditioned reflex. New York: Macmillan.

SPARKS, D. L. (1988). Neural cartography: Sensory and motor maps in the superior colliculus. Brain. Behavior \& Evolution, 31, 49-56.

SPARKS, D. L., \& HarTwiCh-Young, R. (1989). The deep layers of the superior colliculus. In R. Wurtz \& M. E. Goldberg (Eds.), The neurobiology of saccadic eve movements (pp. 213-255). Amsterdam: Elsevier. 
SPENCE, C. J., \& DRIVER, J. (1994). Covert spatial orienting in audition: Exogenous and endogenous mechanisms facilitate sound localization. Journal of Experimental Psychology: Human Perception \& Performance, 20, 555-574.

SPENCE, C. J., \& Driver, J. (1996). Audiovisual links in endogenous covert spatial attention. Journal of Experimental Psychology: Human Perception \& Performance, 22, $1005-1030$.

SPERLING G. (1984). A unified theory of attention and signal detection. In R. S. Parasuraman \& D. R. Davies (Eds.), Varieties of attention (pp. 103-181). New York: Academic Press.

STEIN, B. E. (1984). Multimodal representation in the superior colliculus and optic tectum. In H. Vanegas (Ed.), Comparative neurology of the optic tectum (pp. 819-841). New York: Plenum.

Stein, B. E., \& ClamanN, H. P. (1981). Control of pinna movements and sensorimotor register in cat superior colliculus. Brain, Behavior \& Evolution, 19, 180-192.

Stein, B. E., \& Meredith, M. A. (1993). The merging of the senses. Cambridge, MA: MIT Press.

Stein, B. E., Wallace, M. T., \& Meredith, M. A. (1995). Neural mechanisms mediating attention and orientation to multisensory cues. In M. S. Gazzaniga (Ed.), The cognitive neurosciences (pp. 683-702). Cambridge, MA: MIT Press.

Strybel, T. Z., Witty, A. M., \& Perrott, D. R. (1992). Auditory apparent motion in the free field: The effects of stimulus duration and separation. Perception \& Psychophysics, 52, 139-143.

Tassinari, G., Aglioti, S., Chelazzi, L., Peru, A., \& Berlucchi, G. (1994). Do peripheral non-informative cues induce early facilitation of target detection? Vision Research, 34, 179-189.

Thompson, G. C., \& Masterton, R. B. (1978). Brain stem auditory pathways involved in reflexive head orientation to sound. Journal of Neurophysiology, 41, 1183-1202.

TiaO, Y.-C., \& Blakemore, C. (1976). Functional organization in the superior colliculus of the golden hamster. Journal of Comparative Neurology, 168, 483-504.

Treisman, A. M., \& Gelade, G. (1980). A feature-integration theory of attention. Cognitive Psychology, 12, 97-136.
Umiltà, C., \& Nicoletti, R. (1985). Attention and coding effects in S-R compatibility due to irrelevant spatial cues. In M. I. Posner \& O. S. M. Marin (Eds.), Attention and performance XI (pp. 457-471). Hillsdale, NJ: Erlbaum.

WARD, L. M. (1994). Supramodal and modality-specific mechanisms for stimulus-driven shifts of auditory and visual attention. Canadian Journal of Experimental Psychology, 48, 242-259.

Withington, D. J. (1992). The effect of binocular lid suture on auditory responses in the guinea-pig superior colliculus. Neuroscience Letters, 136, 153-156.

Withington-Wray. D. J., Binns, K. E., Dhanjal, S. S., Brickley, S. G., \& Keating, M. J. (1990). The maturation of the superior collicular map of auditory space in the guinea pig is disrupted by developmental auditory deprivation. European Journal of Neuroscience, 2, 693-703.

Wurtz, R. H., Goldberg, M. E., \& Robinson, D. L. (1982). Brain mechanisms of visual attention. Scientific American, 246 (6), 100-107.

\section{NOTES}

1. In fact, the advantage for valid trials over invalid trials at short SOAs often reverses to become a disadvantage at longer SOAs $(>300 \mathrm{msec})$ in uninformative spatial cuing studies within vision-the phenomenon of so-called "inhibition-of-return" (e.g., Posner \& Cohen, 1984). However, we have never observed this valid disadvantage at long SOAs in the present elevation task, across more than 10 experiments using uninformative peripheral cues. We are currently preparing a manuscript concerned with the situations and modalities in which inhibition-of-return is observed.

2. Our thanks are extended to Roger W. Remington for raising this possibility.

(Manuscript received November 15, 1994; revision accepted for publication February 24, 1996.) 